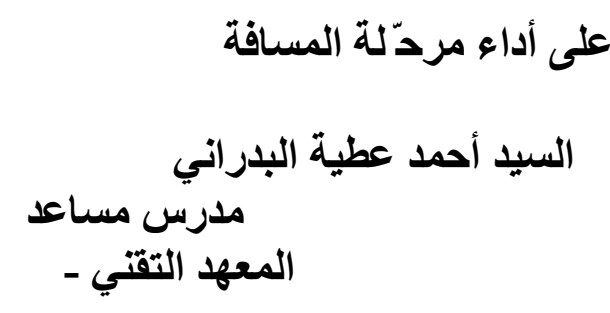

تأثير الحث التبادلي لنظام التعاقب الصفري علي

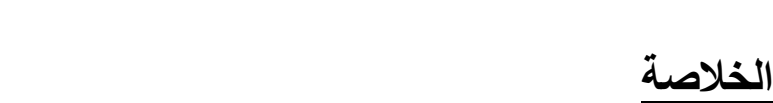

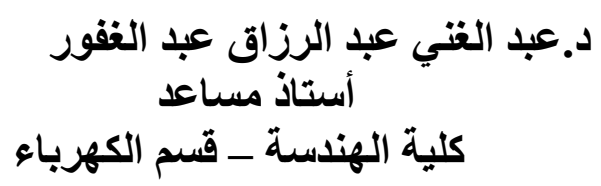

قسم الكهرباء

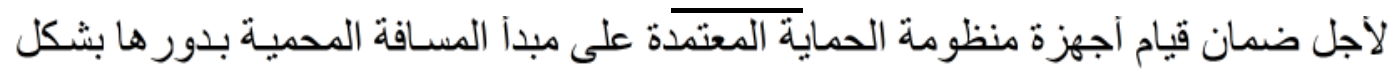

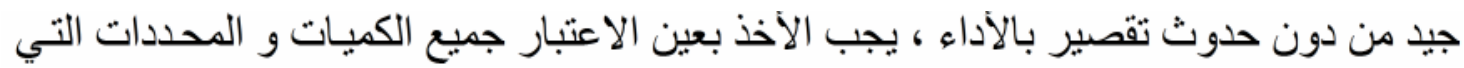

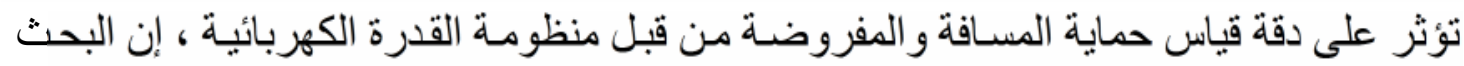
يتناول المشكلة التي تواجها مرحّلة المسافة التقليديـة (Conventional Distance Relay)

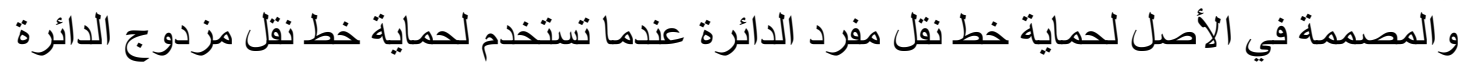

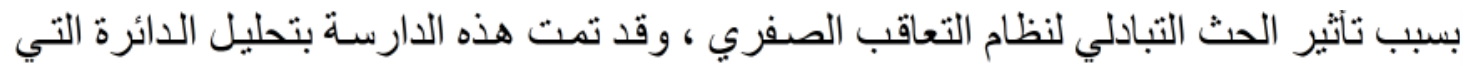

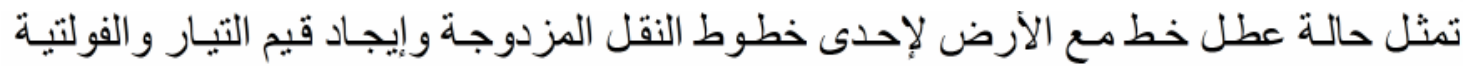

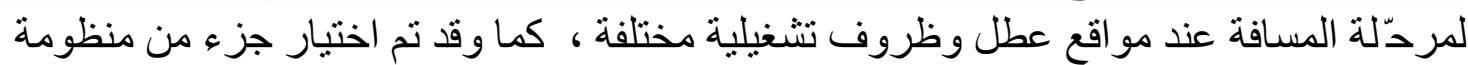

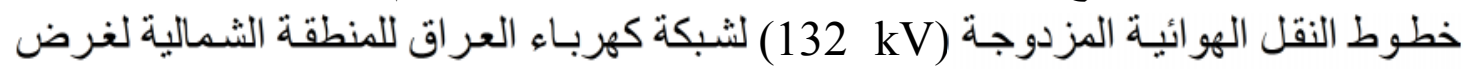
إجر اء هذا البحث.

وقد أظهرت نتائج البحث أن الحث التبادلي لنظـام التعاقب الصفري سوف يجعل مرحّلة

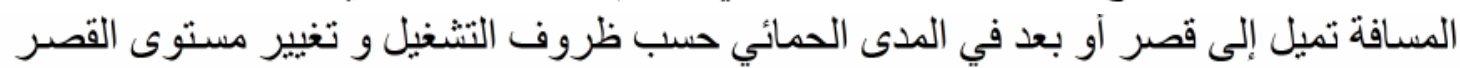

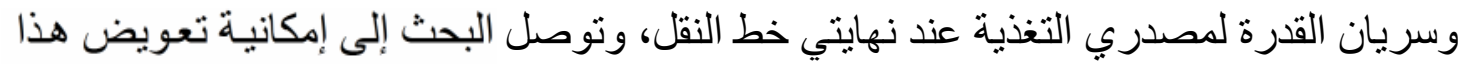

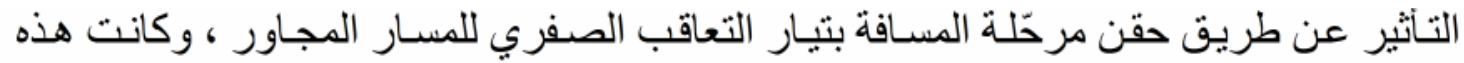

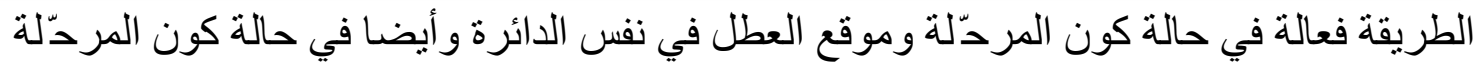
وموقع العطل في دائرة مختلفة ولكن بمحددات.

\title{
Influence of Mutual Coupling due to Zero-Sequence On The Performance of Distance Relay
}

\section{Dr. Abdul Ghani A. Abdul Ghafoor Mr. Ahmed Ateya Al-Badrany Electrical Department College of Engineering Electrical Department Technical Institute}

Abstract

To get accurate performance of the distance protection function, Must be all influencing quantities and limitations on the measuring accuracy of distance relay that imposed by power system in considered. This research includes study and analysis of the problems which faces the conventional distance relay which was designed for single circuit distance protection when applied double circuit of over head transmission line, 
due to mutual coupling zero - sequence system in this case, For various operational conditions and fault location, This work had been conducted with (I.N.R.G. $132 \mathrm{kV}$ ) transmission lines systems under to ground fault condition, The current and voltage at the relay and fault location were calculated.

The results show that zero sequence mutual coupling may cause the distance relay to seriously over reach under reach for different operational situations and fault locations, Values of short circuit levels ratio and power flow for feed sources which connected to the line ends have major effect in this problem.

This research indicate the possibility of zero sequence coupling compensation by injecting proportion of the zero sequence current flowing in the parallel feeder into the relay to reduce this effect, This method is successful when relay and fault location are in the a same circuit, Also when relay and fault location are in different circuits but with limits .

Keywords: Protection, Distance Relay, Influence of Mutual Coupling.

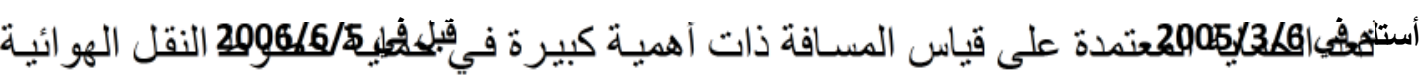

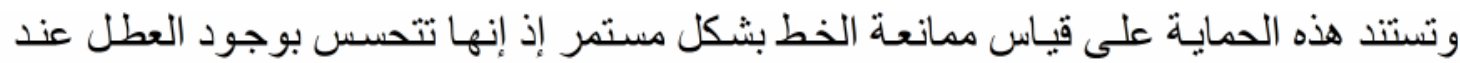

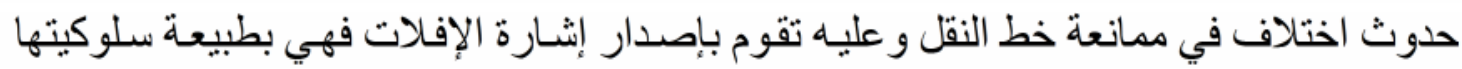
تعد حماية غير وحدوية.

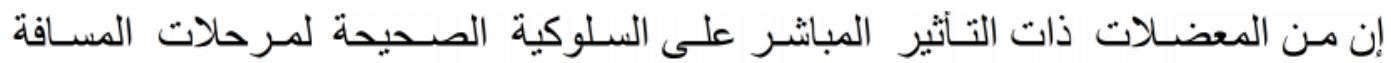

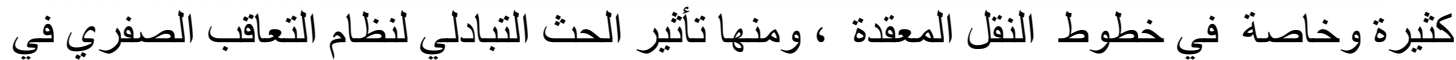
خطوط النقل المزدوجة في [1]

2 ـ تأثير الحث التبادلى في خطوط النقل الهوائية المزدوجة الدائرة:

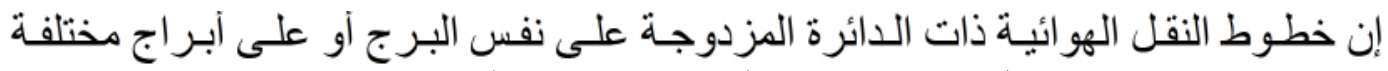

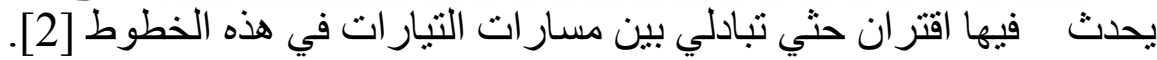

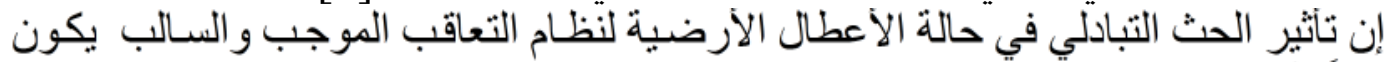

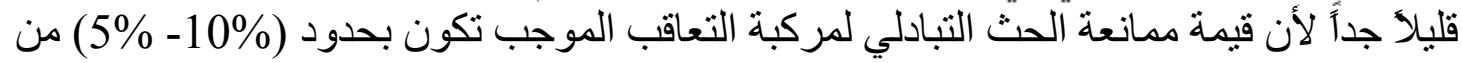

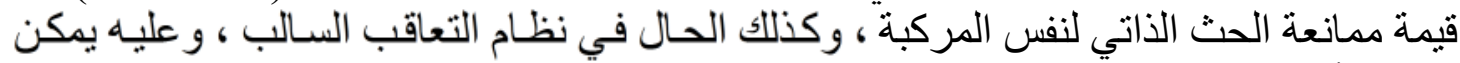

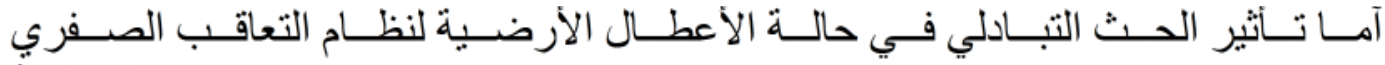

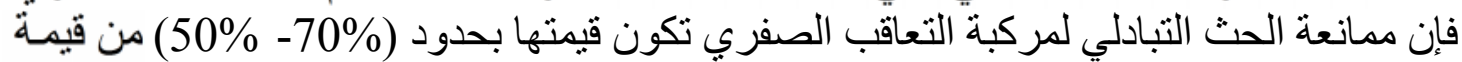

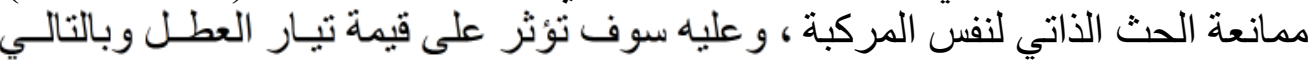

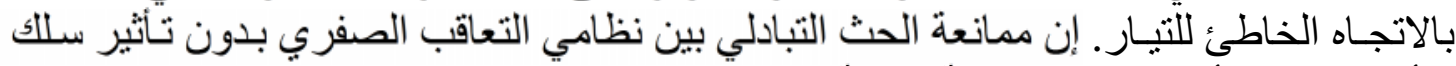
التأريض يمكن أن تعطى بالمعادلة التالية][2]:

$$
\mathrm{Z}_{\mathrm{OM}}=3 . \mathrm{R}_{\mathrm{E}}+\left(\mathrm{j} . \omega .6 \cdot \ell_{n} \frac{D_{e}}{A_{L}}\right) \cdot 10^{-4}[\Omega / \mathrm{km}] \ldots(2-1)
$$


، للنظـــام (Angular Frequency) تمثـــل التــردد الــز اوي ( $\omega=\mathrm{f} \pi$ 2)

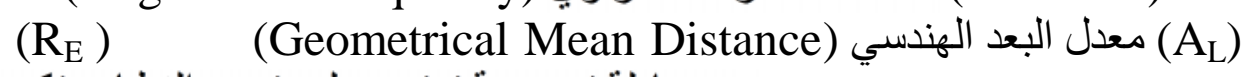

و وهي معادلة تجريبية تعتمد على تردد النظام وتكون وفق (Ground Resistance )

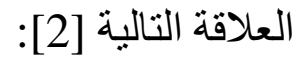

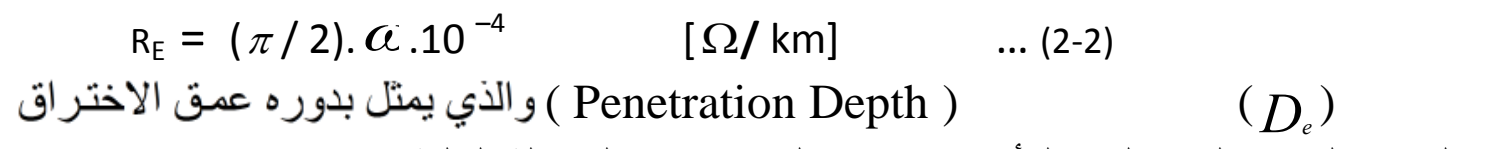

المكافئ لمسار التيار العائد للأرض ويمكن التعبير عنه بالمعادلة التالية [2]:

$D_{e}=1650 \sqrt{\frac{\rho}{\omega}}$

حيث إن (م ) تمثل المقاومة النوعية للأرض (Specific Resistance of Earth)

3 ـ طر ائق تعويض تأثثر مركبة نظام التعاقب الصفرى لمرحدّلة قياس المسافة:

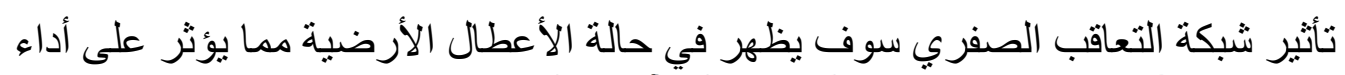

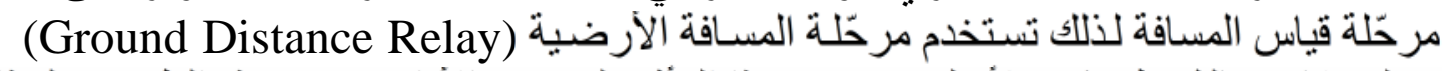

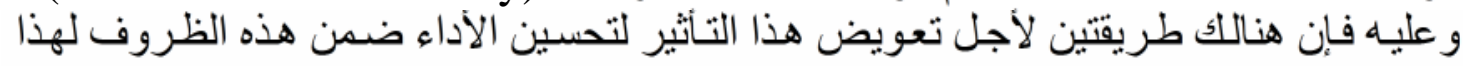

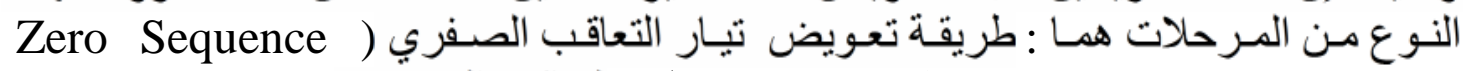

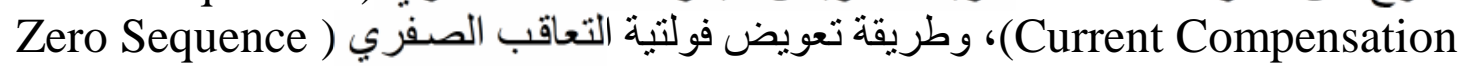
.[3](Voltage Compensation

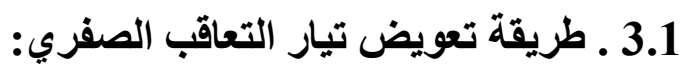



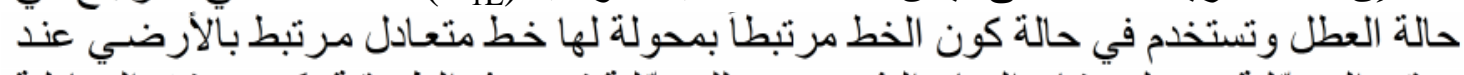

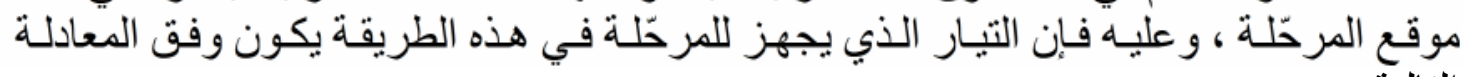
التالية[3]:

$$
I_{\mathrm{R}}=I_{\mathrm{a}}+\left(\frac{Z_{0 L}-Z_{1 L}}{Z_{1 L}}\right) \cdot I_{0}
$$




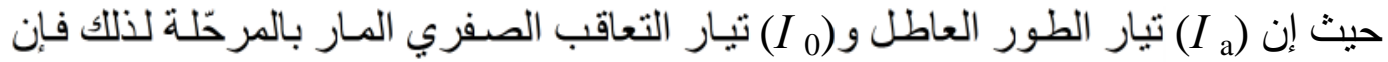
(L-G)

$$
\mathrm{Z}_{\mathrm{R}}=\mathrm{Z}_{1 \mathrm{~L}}+I_{\mathrm{F}} \mathrm{R}_{\mathrm{F}} /\left(I_{\mathrm{a}}+\left(\frac{Z_{0 L}-Z_{1 L}}{Z_{1 L}}\right) \cdot I_{0}\right)
$$

3.2 ـ طريقة تعويض فولتية التعاقب الصفري:

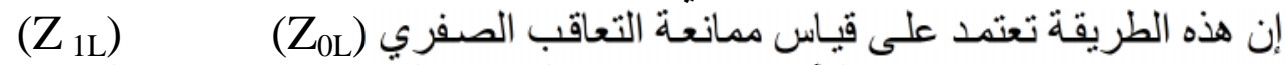

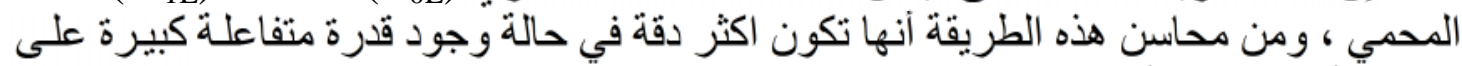

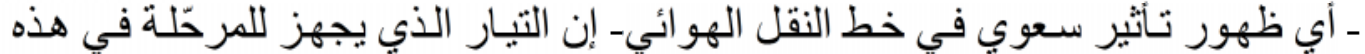

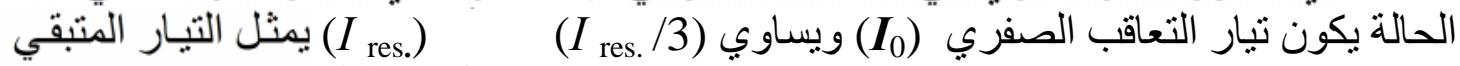

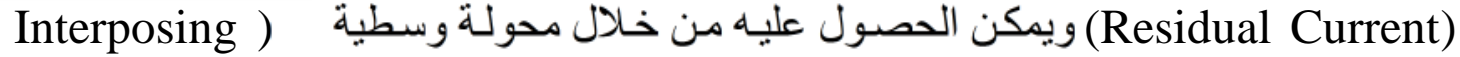
Transformer ) لذلك فإن الممانعة التي تقيسها المرحّلة في حالة عطل (L-G) يمكن كتابتها $\mathrm{Z}_{\mathrm{R}}=\mathrm{Z}_{0 \mathrm{~L}}+\left(I_{\mathrm{F}} / I_{0}\right) \cdot \mathrm{R}_{\mathrm{F}}$

4ظظروف تثشيل مرحّلة قياس المسافة فى خطوط النقل الهو ائية المزدوجة:

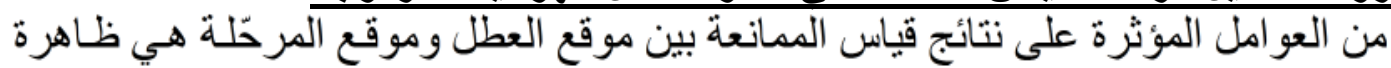

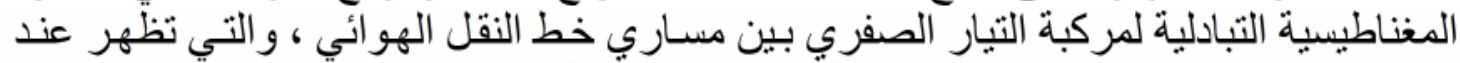

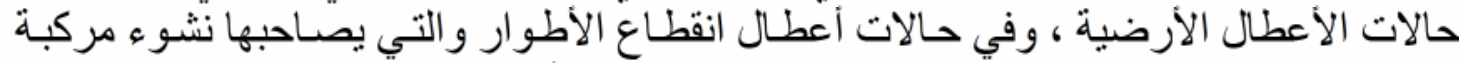

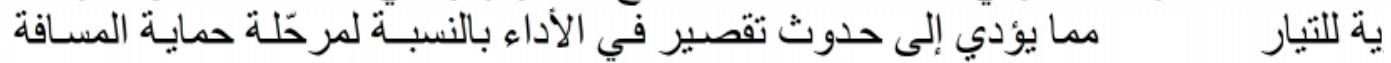

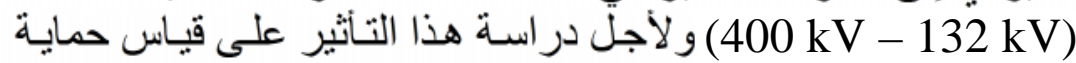

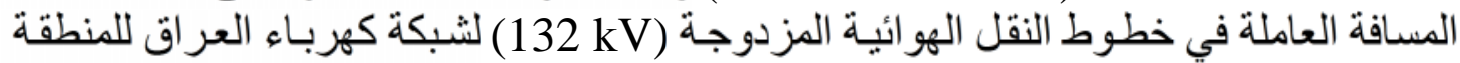

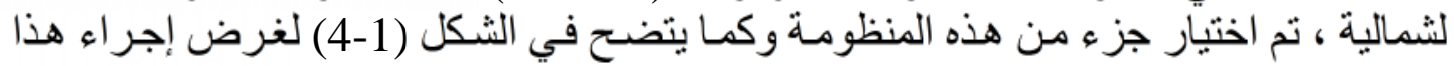

إن لمستوى القصر عند قضبان العمومي للمحطات تأثير ا كبير ا على تبار ات الحث التبادلي

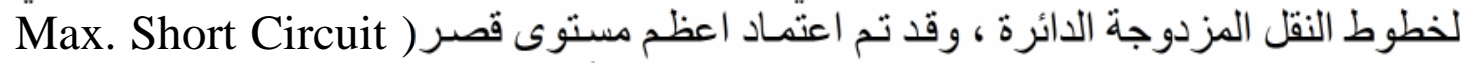
(Level

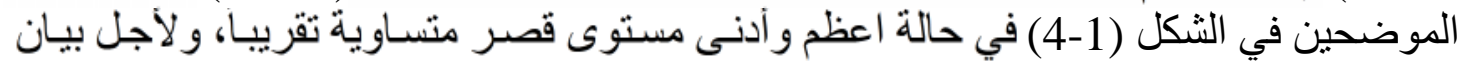

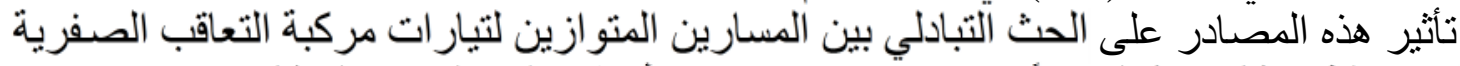

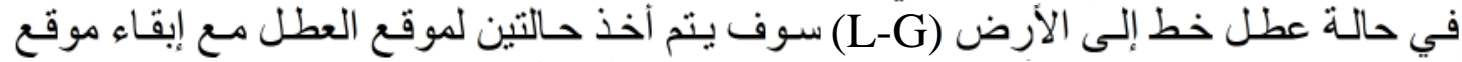

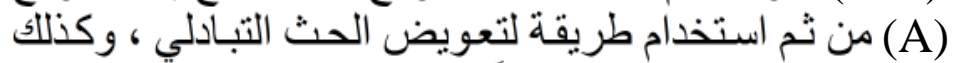
سوف ينم أخذ الحالة عندما يكون أحد الخطين المتوازين مؤرضاً من طرفيه. 


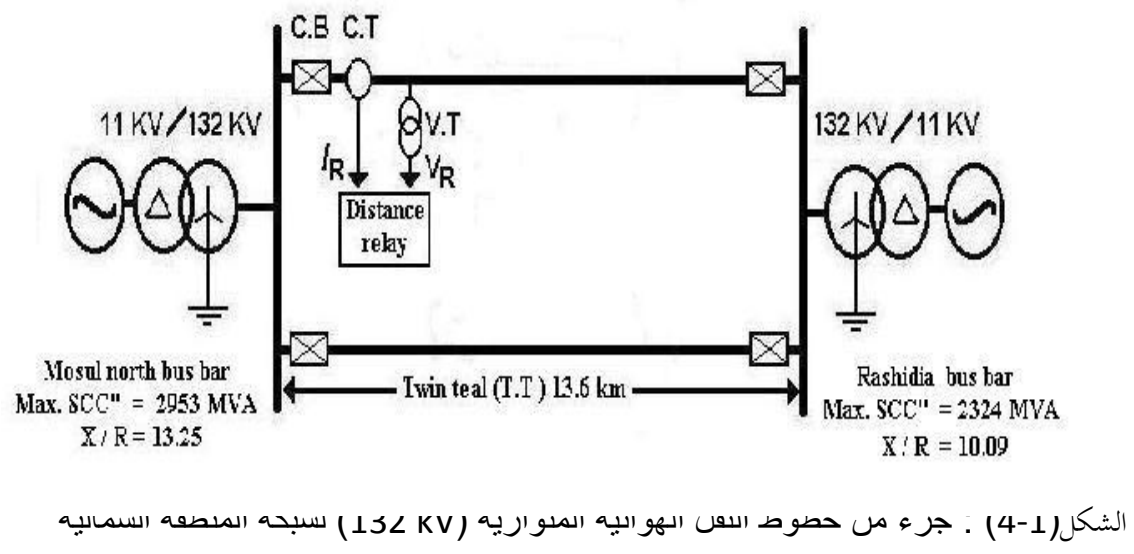

4.1 ـ التحليل الرياضي لحالة عطل طور مع الأرض في مسار الدائرة(A):

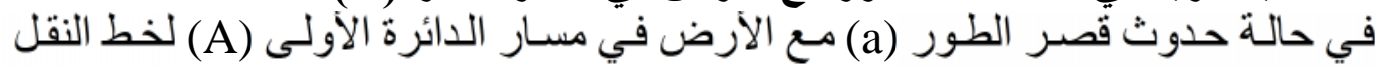

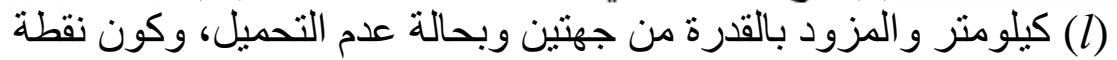

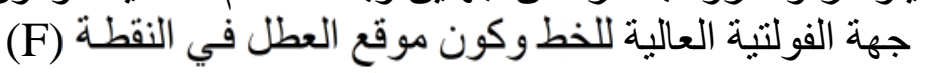
(X) كيلومتر من موقع مرحّلة المسافة وكما موضح في الثكل (2-4) [4].

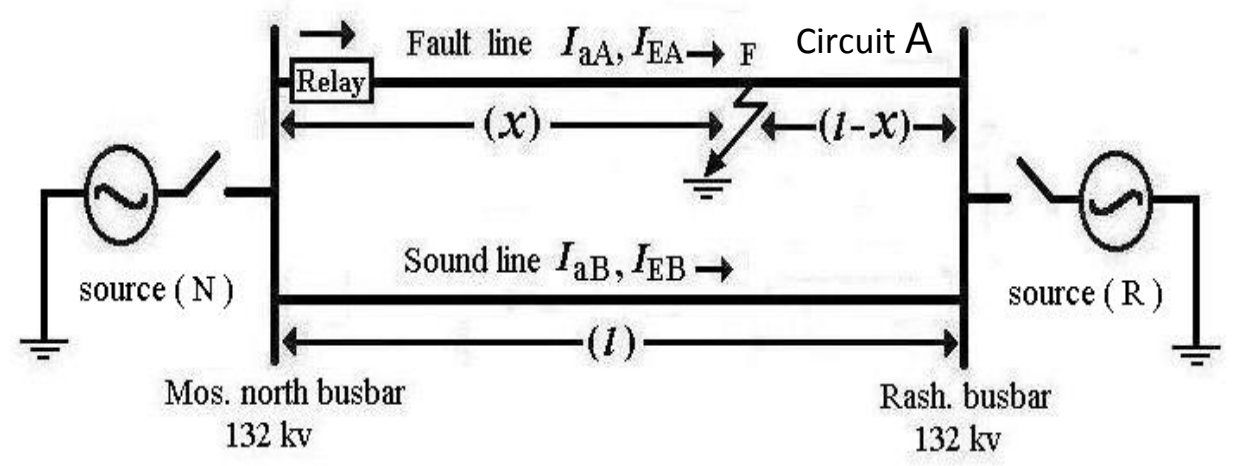

الشكل (4-4): خط نقل مزدوج في حالة عطل (L-G) في مسار الدائرة (A)

و عليه فإن فرق الجهد لنظام التعاقب الموجب و الذي يظهر عبر مرحّلة قياس المسافة يكون

$$
\mathrm{V}_{1 \mathrm{R}}=\mathrm{X} \cdot \mathrm{Z}_{1 \mathrm{~L}} \cdot \mathrm{I}_{1 \mathrm{~A}}+\mathrm{V}_{1 \mathrm{~F}}
$$

لجهد لنظام التعاقب السالب و الذي يعبر عنه بالعلاقة التالية :

$$
\mathrm{V}_{2 \mathrm{R}}=\mathrm{X} \cdot \mathrm{Z}_{2 \mathrm{~L}} \cdot \mathrm{I}_{2 \mathrm{~A}}+\mathrm{V}_{2 \mathrm{~F}}
$$


إن تيار التعاقب الموجب للمرحّلة يكون مسـاويا لتبار التعاقب السـالب (

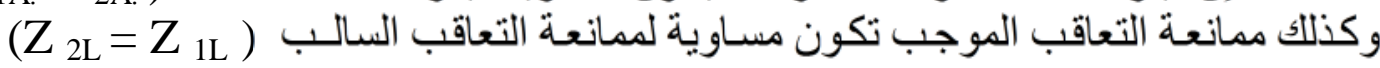
كيلومثر لخط أنطان

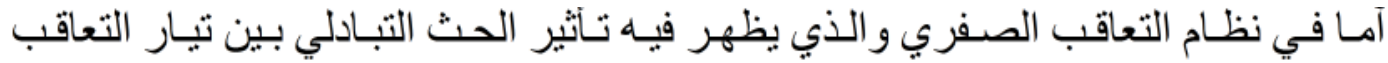

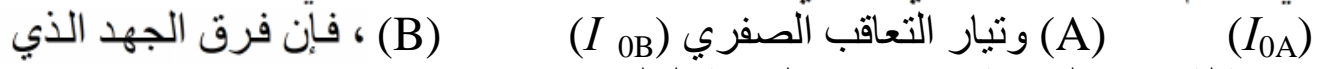
يظهر عبر مرحدّلة قياس المسافة يكون وفق العلاقة التالي: $\mathrm{V}_{\mathrm{OR}}=\mathrm{X} \cdot \mathrm{Z}_{\mathrm{OL}} \cdot I_{\mathrm{OA}}+\mathrm{X} \cdot \mathrm{Z}_{\mathrm{OM}} \cdot I_{\mathrm{OB}}+\mathrm{V}_{\mathrm{OF}}$

و عليه فإن فولتية المرحّلة ( $)$ سوف تتثمل هبوط الجهد لمركبات التعاقب الثلاثة بما فيها $V_{R}=V_{1 R}+V_{2 R}+V_{O R}+V_{1 F}+V_{2 F}+V_{0 F} \quad \ldots$ فولتية مقاومة العطل وكالتالي : (4-4)

و على فرض أن مقاومة العطل تساوي صفرا فإن ( 0 (ل) الذي يجهز للمردّلة فيكون بطريقة تيار التعاقب الصفري المذكورة آنفاويكو $I_{\mathrm{R}}=I_{\mathrm{aA}}+\left(\frac{Z_{O L}-Z_{1 L}}{Z_{\mathrm{IL}}}\right) \cdot I_{\mathrm{OA}}$

لذلك فإن قيمة الممانعة الظاهرية ( Apparent Impedance) التي تقبسها مرحّلة المسافة

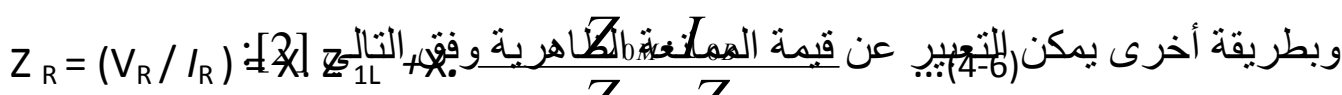

$$
\begin{aligned}
& I_{a A}+\frac{Z_{0 L}-Z_{1 L}}{Z_{1 L}} \cdot I_{0 A} \\
& \mathrm{Z}_{\mathrm{R}}=\mathrm{X} \cdot \mathrm{Z}_{1 \mathrm{~L}}\left\{1+\frac{K_{M} \cdot I_{E B}}{I_{a A}+K_{E} \cdot I_{E A}}\{\right.
\end{aligned}
$$

حيث أن (Kesidual Compensation Factor) يمثل عامل التعويض المتبقي

$$
\text { ويسـاوي }
$$

Mutual Compensation ( يمثل عامل التعويض التبادلي (KM $) \quad\left(\frac{Z_{0 L}-Z_{1 L}}{3 Z_{1 L}}\right)$ 


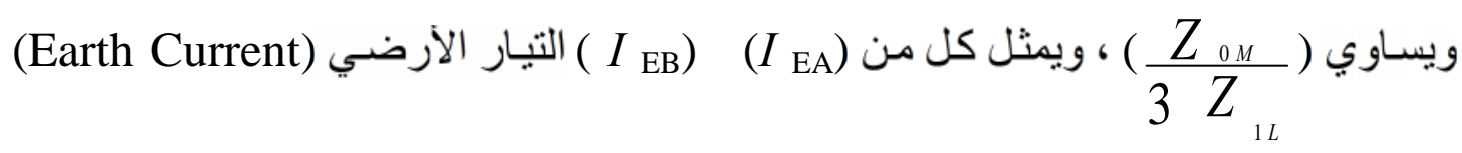
(3.I $\left(I_{\mathrm{EA}}\right)$

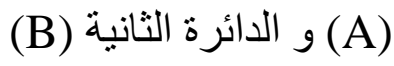

(3.I $\left(I_{\mathrm{EB}}\right)$

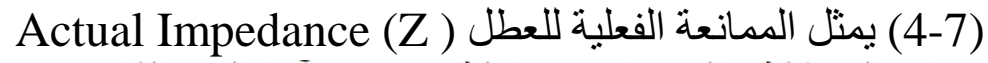

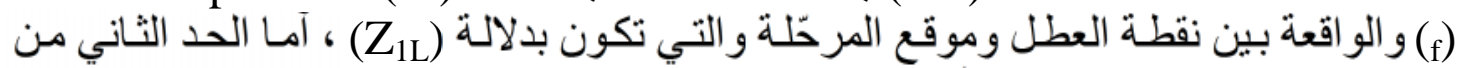

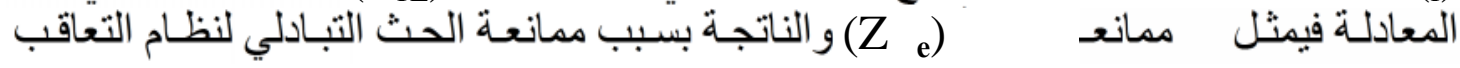
. $\left(\mathrm{Z}_{0 \mathrm{M}}\right)$

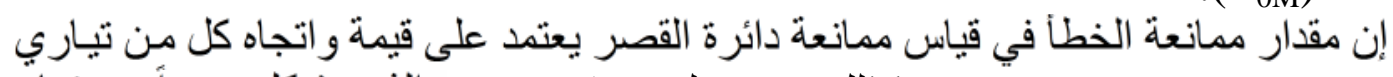

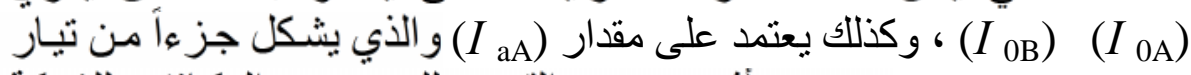



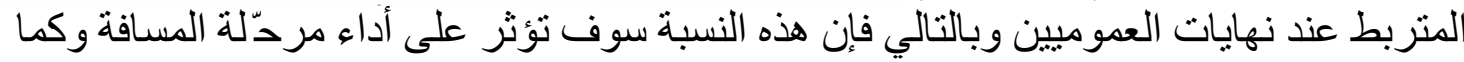

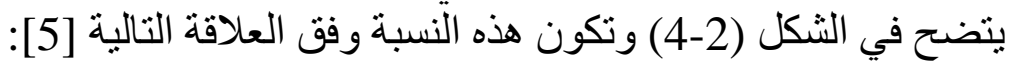

$\left(I_{O B} / I_{O A}\right)=\frac{(m) \cdot Z_{O S R}-(1-m) \cdot\left(Z_{O S N}\right)}{(2-m) \cdot Z_{0 S R}+(1-m) \cdot\left(Z_{O S N}+Z_{O L}+Z_{O M}\right)}$

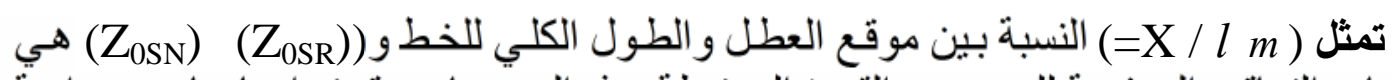

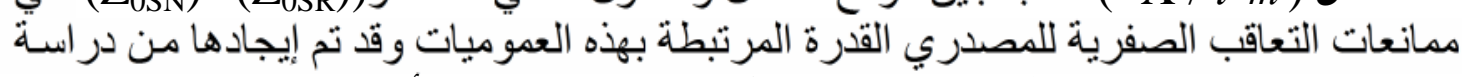

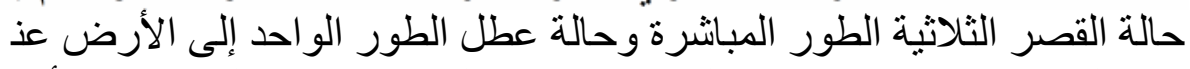

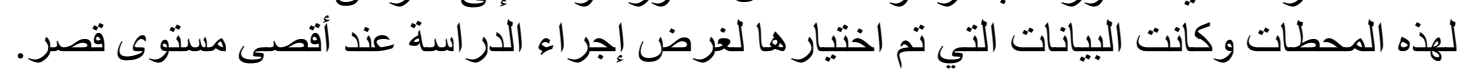

4.2 ـ التحليل الرياضي لحالة عطل طور مع الأرض في مسار الائرة(B):

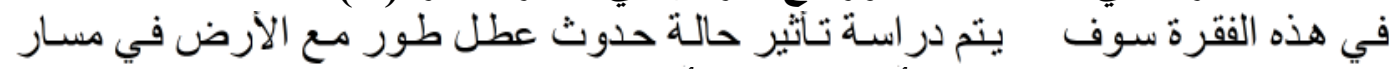

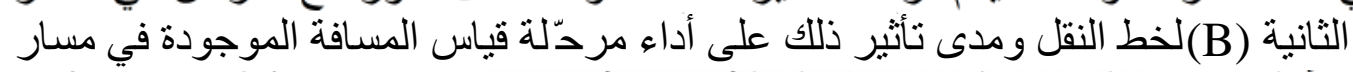

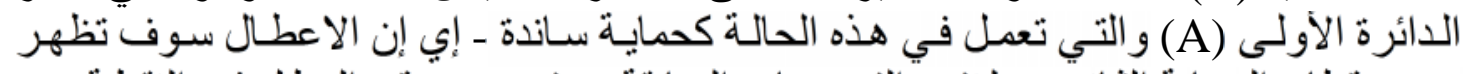

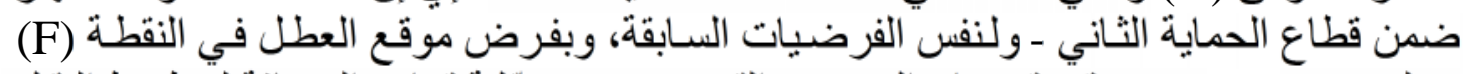

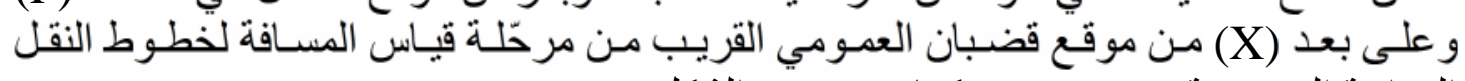
الهو ائية المزدوجة (X) kV (132) وكما يتضح في الثكل (3-4) [4].

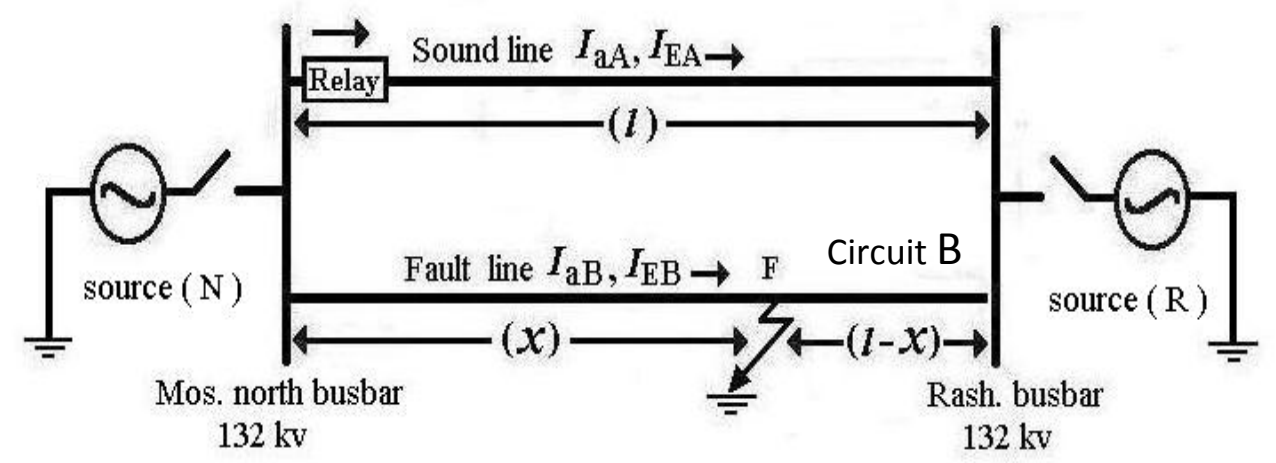

الثكل (4-4): خط نقل مزدوج في حالة عطل (L-G) في مسار الدائرة (B) 
يمكن حسـاب فولتيـة المرحّلـة ( V ) والتـي تثـمل هبوط الجهـ لمركبـات التعاقب الثثلاثـة

$$
\mathrm{V}_{\mathrm{R}}=2(2 I-\mathrm{X}) \mathrm{Z}_{1 \mathrm{~L}} \cdot I_{1 \mathrm{~A}}+2(I-\mathrm{X}) \mathrm{Z}_{1 \mathrm{~L}} \cdot I_{1 S \mathrm{R}}+(2 I-\mathrm{X}) \mathrm{Z}_{\mathrm{OL}} \cdot I_{\mathrm{OA}}+\ldots
$$

$$
(I-\mathrm{X}) \mathrm{Z}_{\mathrm{OL}} \cdot I_{\mathrm{OSR}}+(\mathrm{X}) \mathrm{Z}_{\mathrm{OM}} \cdot I_{\mathrm{OB}}-(I-\mathrm{X}) \mathrm{Z}_{\mathrm{OM}} \cdot I_{\mathrm{OA}}-\ldots
$$

معادلة السابقة تأثير مصدر تبـار التغذية لقضبان العمومي البعيد عن مرحِّلة

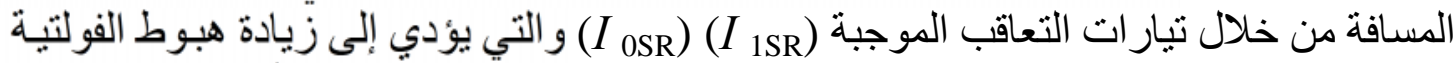

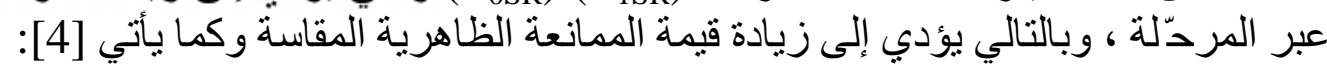
$Z_{R}=Z_{L L}\left\{(2 l-X)+\frac{(l-X)\left[2 Z_{L L} \cdot I_{I S R}+Z_{O L} \cdot I_{O S R}-2 Z_{O M} \cdot I_{0 A}-Z_{O M} \cdot I_{O S R}+X Z_{O M} \cdot I_{0 B}\right.}{I_{a A}+K_{E} \cdot I_{E A}}\right\}$

إن الحد الأول من المعادلة (10-4) يمثل الممانعة الفعلية للعطل ( Actual Impedance

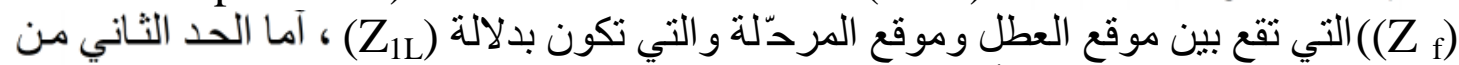

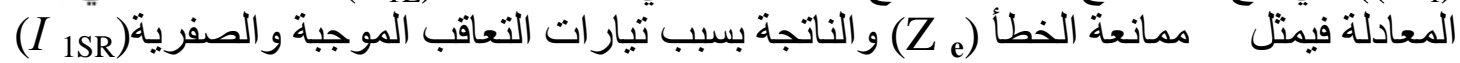

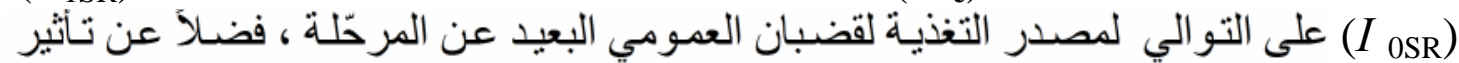

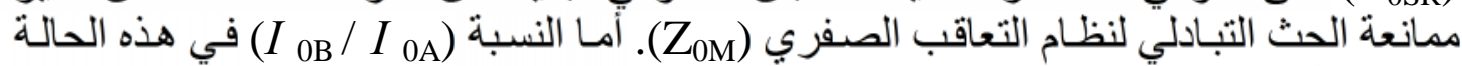

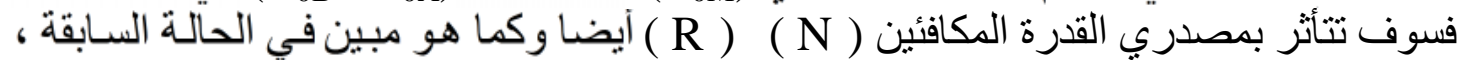
وبالتالي فإن هذه النسبة سوف تؤُثر على أداء مرحّلة المسافة وتكون هذه النسبة وفئق العلاقة

$$
\left(I_{0 \mathrm{~B}} / I_{0 \mathrm{~A}}\right)=\frac{(2-m) \cdot Z_{\text {OSR }}+(1-m) \cdot\left(Z_{\text {OSN }}+Z_{\text {Ol }}+Z_{\text {OM }}\right)}{(m) \cdot Z_{\text {OSR }}-(1-m) \cdot\left(Z_{\text {OSN }}\right)}
$$

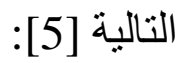

\section{5 ـ تعويض تأثير الحث التبادلى لنظام التعاقب الصفري في خطوط النقل المزدوجة:}

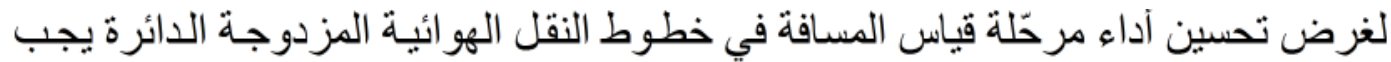

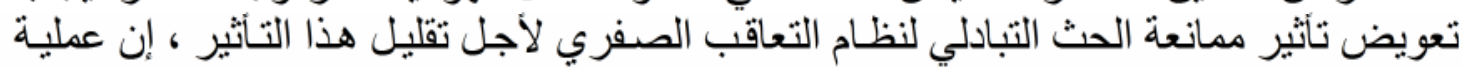

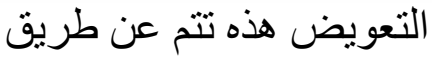

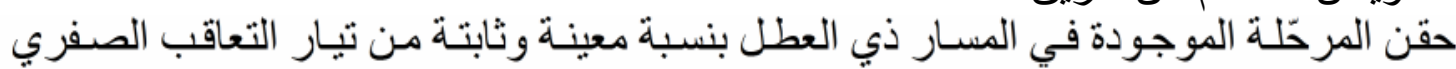

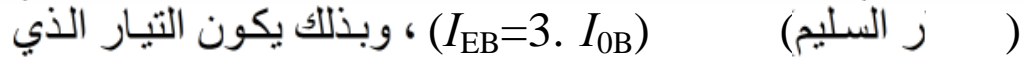
يجزز للمرحدّلة في حال التعويض كالتالي[6]:

$$
I_{\mathrm{R}}=I_{\mathrm{aA}}+I_{\mathrm{EA}} \cdot \mathrm{K}_{\mathrm{E}}+I_{\mathrm{EB}} \cdot \mathrm{K}_{\mathrm{M}}
$$

تمثل عامل التعويض التبادلي ، إن عملية التعويض يمكن أن تستخدم لخطوط

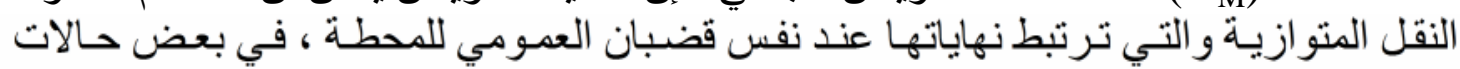




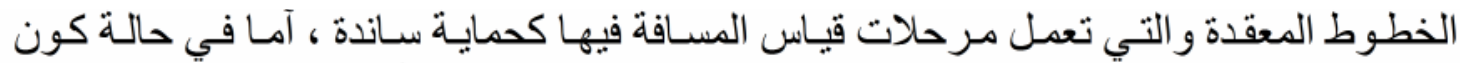

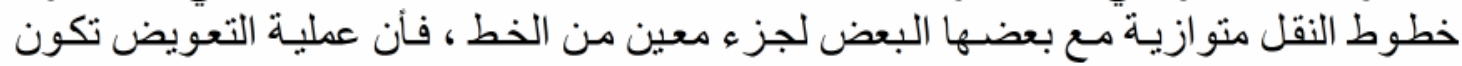

وفي حالة كون مرحّلة قياس المسافة الكتروميكانيكية (Electro-Mechanical Relay)

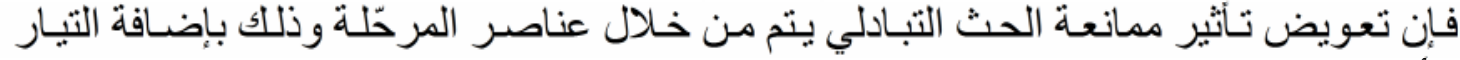

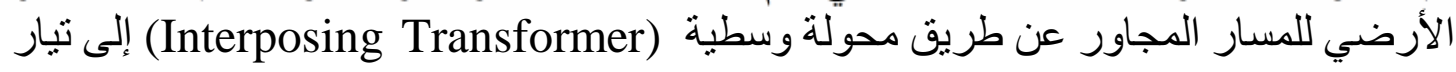

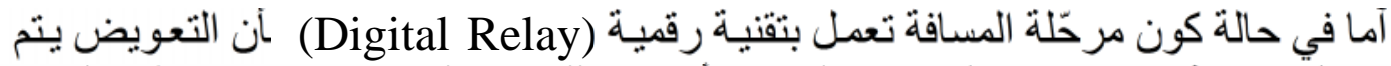

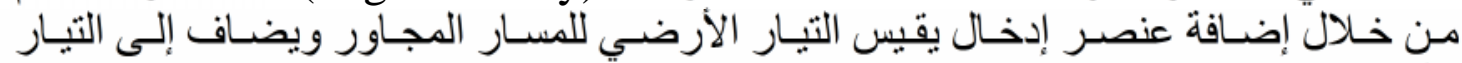

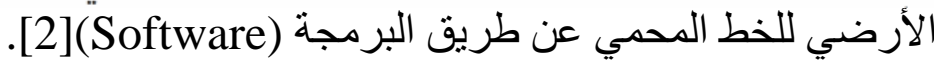

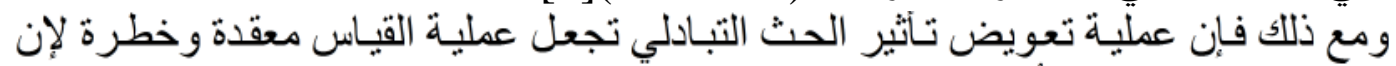
.[1] مرحّلة قياس المسافة سوف نُجهز بتيار ات من محو لات تيار (C.T)

6 ـ بيان تأثير ممانعة الحث التبادلى لنظام التعاقب الصفري على طول منطقة الحماية:

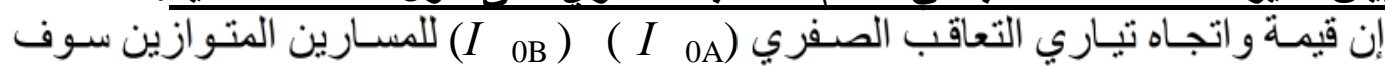

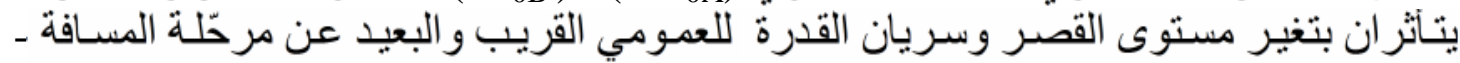

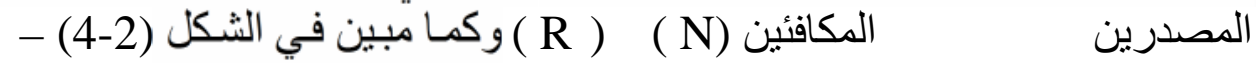

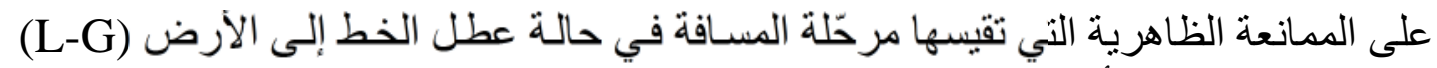
لذا سوف نقوم بيبان نأثير هذه الدصادر على تغيير قيم طول منطقة الحماية.

\subsection{6الة عطل طور مع الأرض في مسار الدائرة(A):}

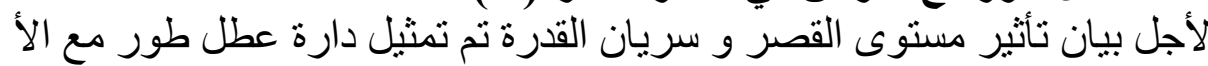

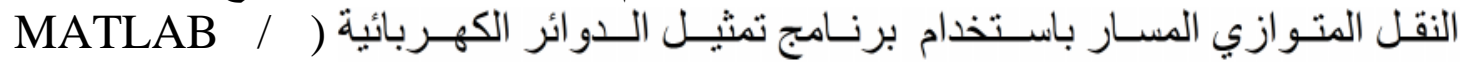

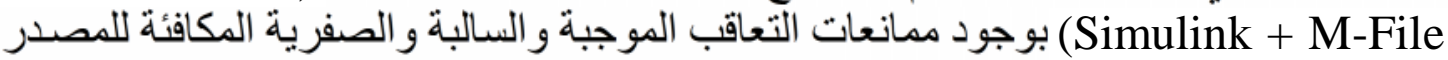
وظروف تشغيلية مختلفة [7]. المرتبط إلى طرفي خط النقل وتم تنفيذه

-6.1.1.تأثير مصدر القدرة القريب من مرحدّلة المسافة:

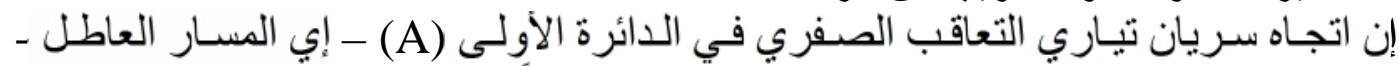

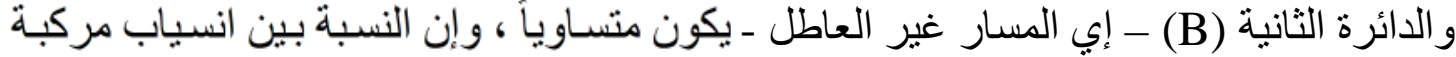
هذين التيارين

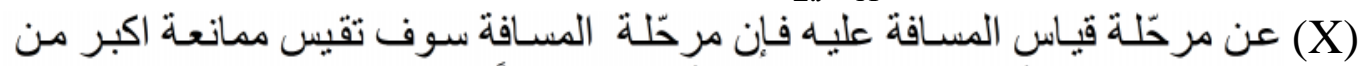

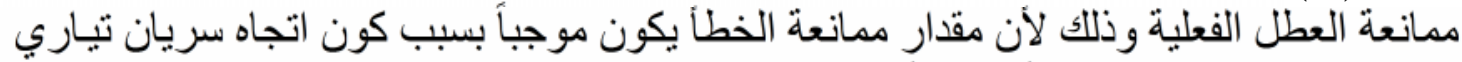

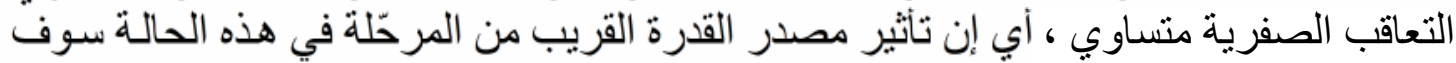


منطقة الحماية الأولى (1st. Zone) الفعلي ، فأنه سوف يغطي (68.5) فقط من الطول الفعلي لخط النقل ، و وعليه فـإن المرحّلة يصل إلى (Under Reach) 
إن اتجاه تيار التعاقب الصفري (I OB ) للمسـار غير العاطل لهذه الحالة يكون مسـاوياً لتيار

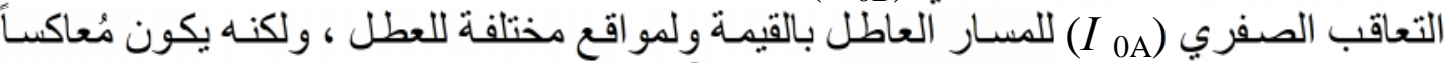

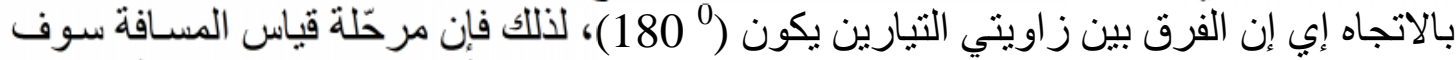

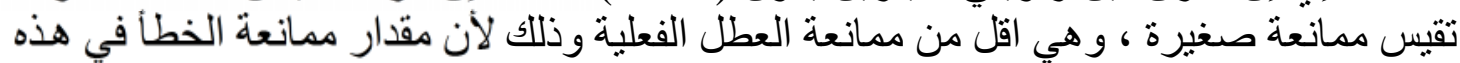

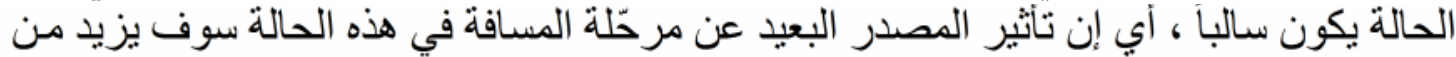

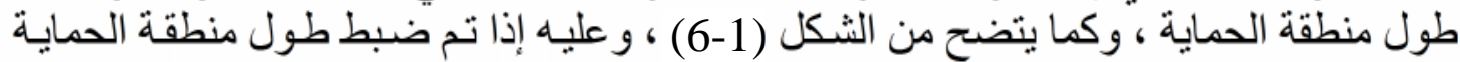
مسار خط النقل الأول الفعلي فإنها

$(53.1 \%)$

(1st. Zone)

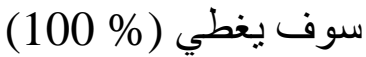

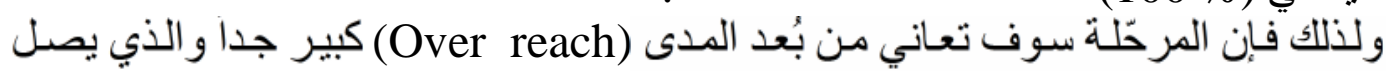

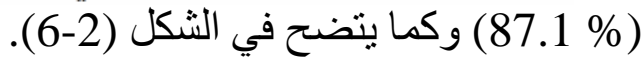

6.1.3. تأثير مصدري القدرة عند نهايتي خط النقل على مرحدّلة المسافة:

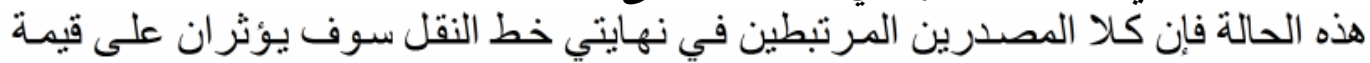

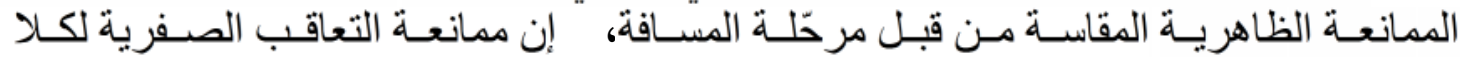

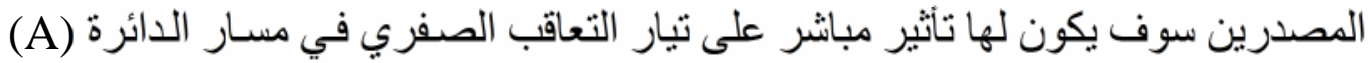

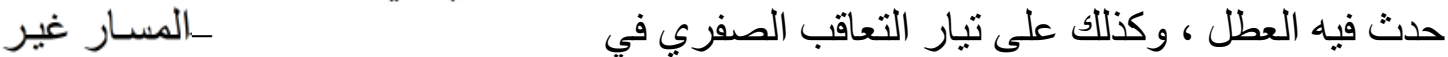

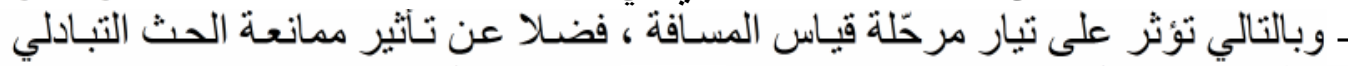

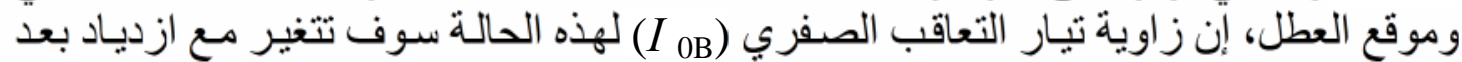

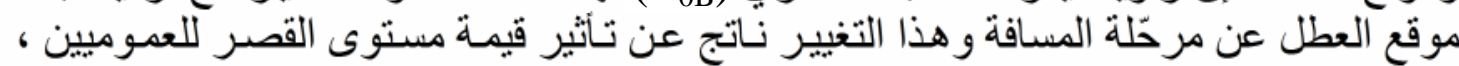

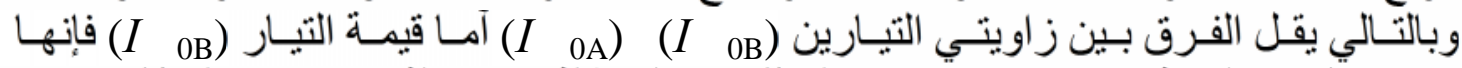

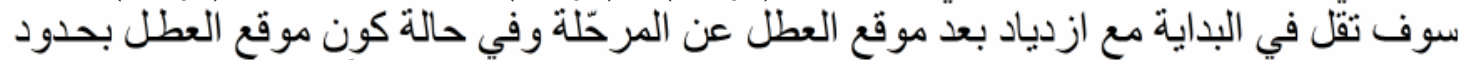

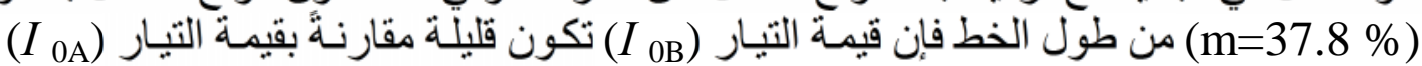

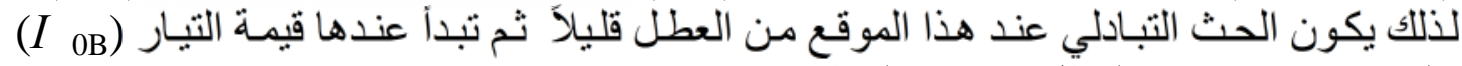

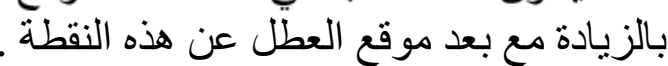

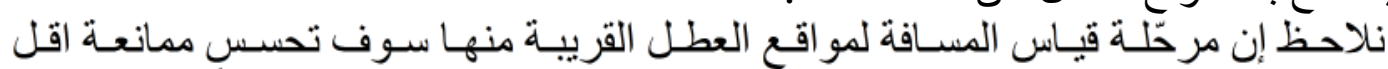

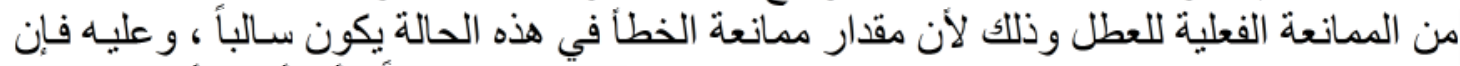
(Over Reach)
(6-2)

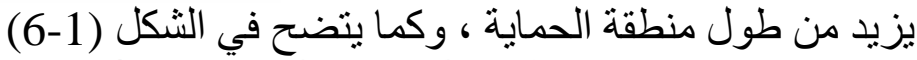

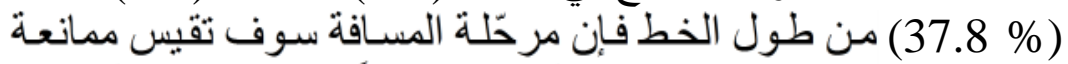

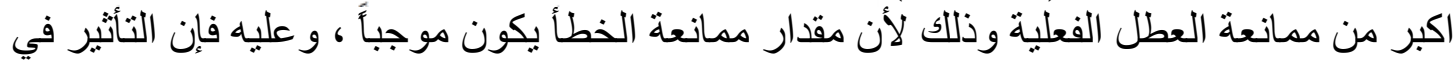

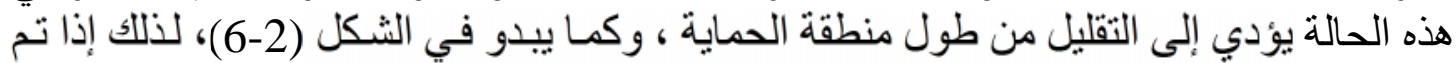
(85\%)

ضبط طول منطقة الحماية الأولى (1st. Zone)

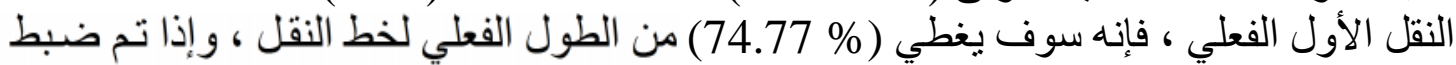

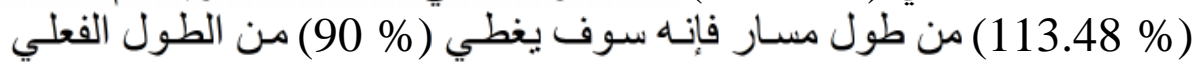

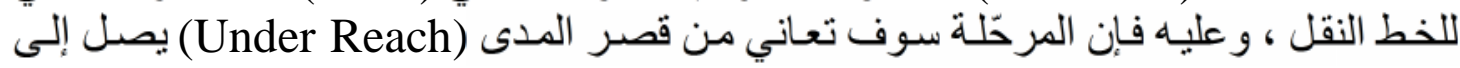
. $29.5 \%)$

يتضح مما سبق أن التنظيم لـ (1 \% 113.48) من طول مسـار النقل الأول غير كاف لفصل

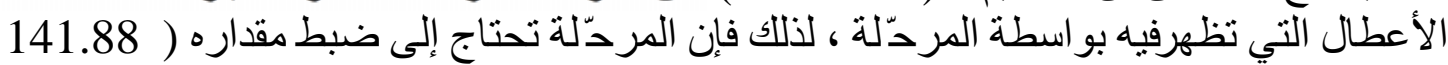

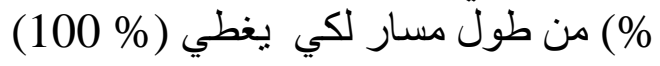

6.2 ـ حالة عطل طور مع الأرض في مسار الدائرة(B):: 
في هذه الحالة سوف ينت بيان تأثير مستوى القصر وسريان القدرة على مقدار ممانعـة الخطاً

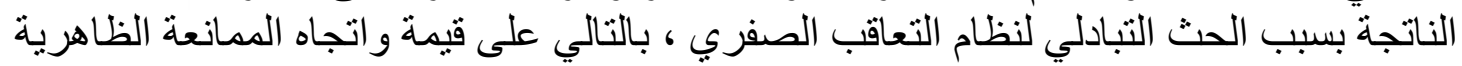

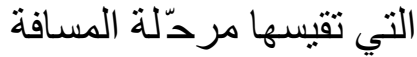




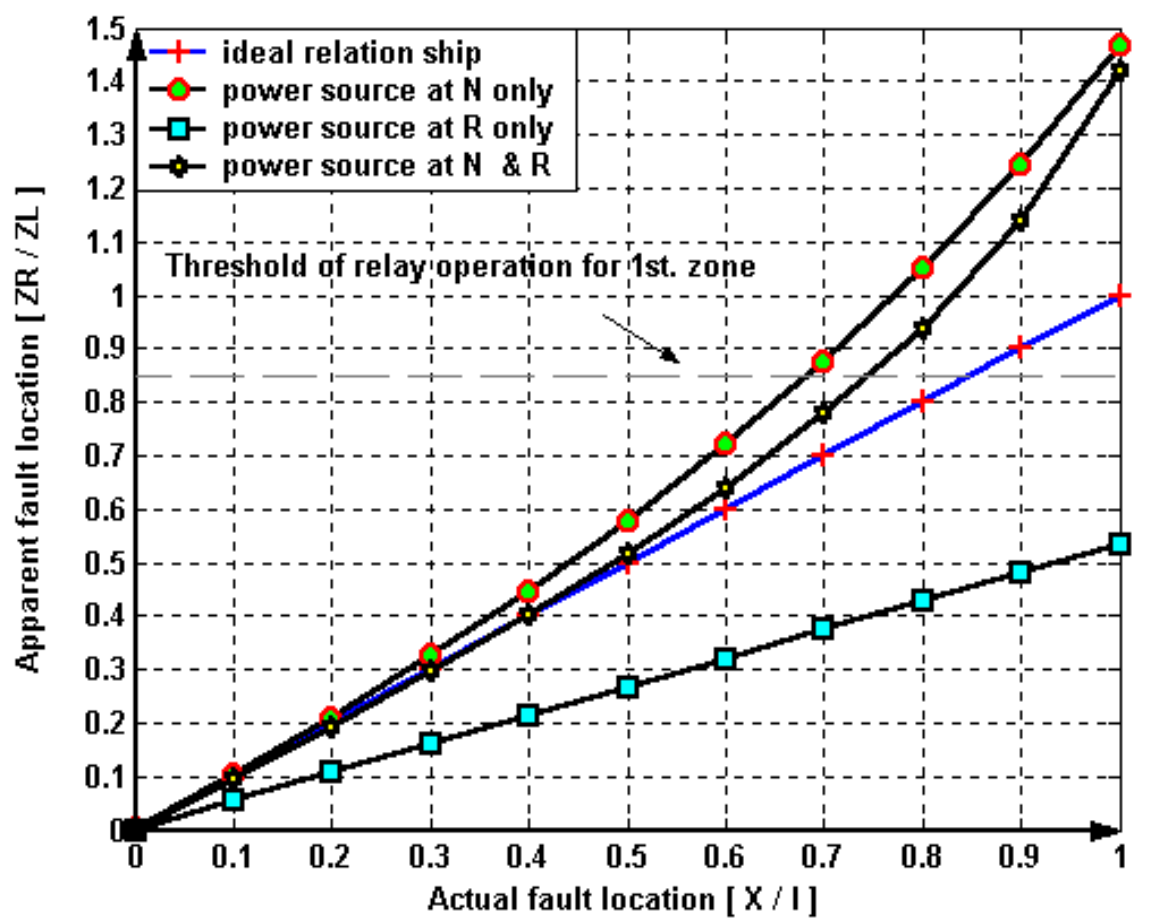

الثكل (1-6) : تأثثر الحث التبادلي لنظام التعاقب الصفري على طول منطقة الحماية

لمرحّلة المسافة في حالة العطل على مسار الدائرة الأولى (A) لمئى

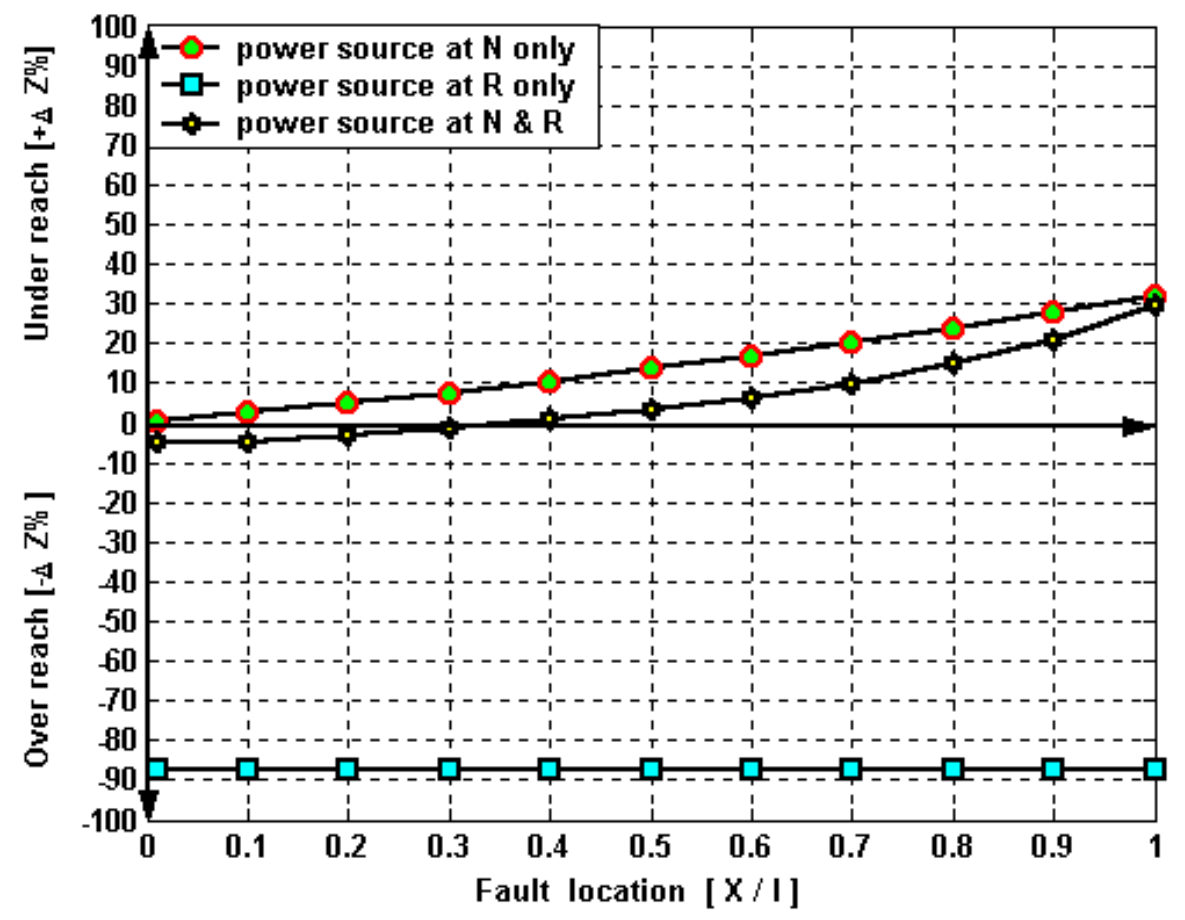

الثكل (2-6) : قيم المدى الحمائي لمرحّلة المسافة في حالة العطل على مسار الدائرة (A) 

إذ إن الأعطال في هذه الحالة سوف تظهر ضمن قطاع الحماع الحماية

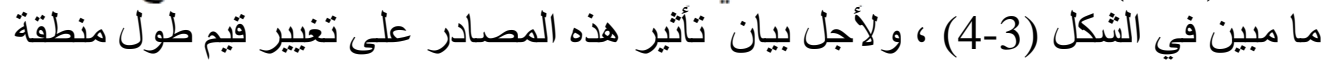

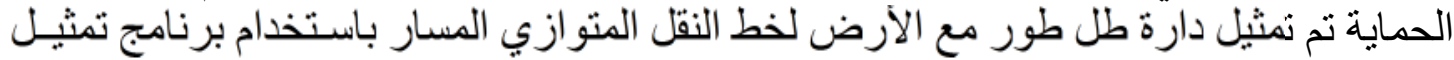

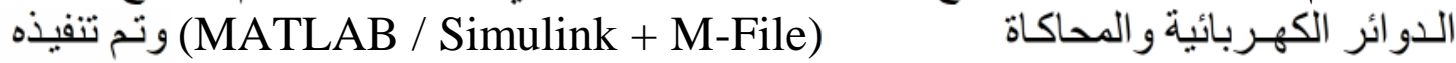
مو اقع عطل وظروف تشغيلية مختلفة وبنفس الأسلوب السابق [7].

l 6.2.1 تأثير مصدر القدرة القريب من مرحدّلة المسافة:

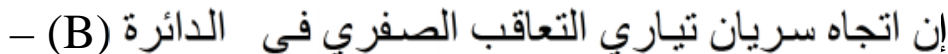

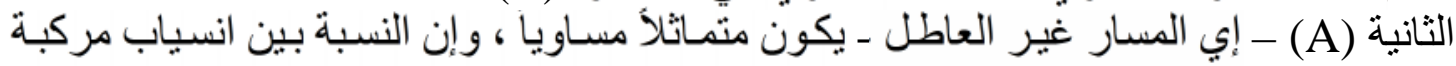
هذين التيارين (A)

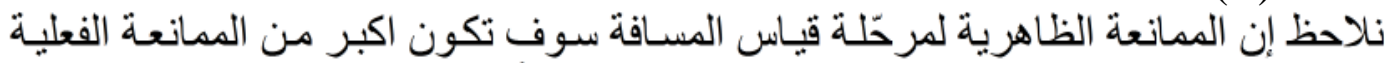

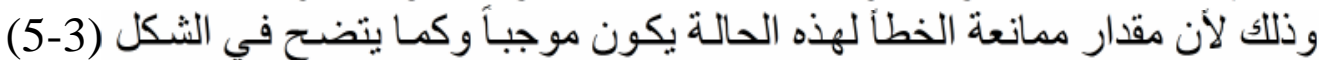

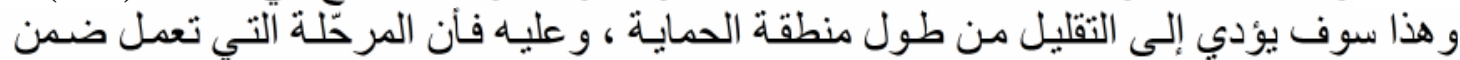

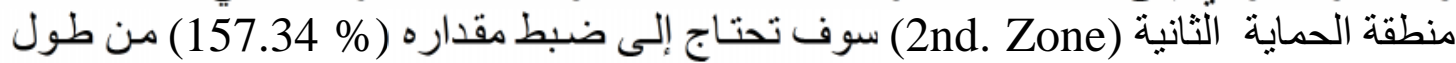

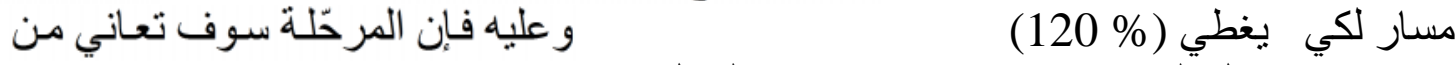
قصر مدى يصل إلى (\% (33) وكما يتضح في الثكل (4-6).

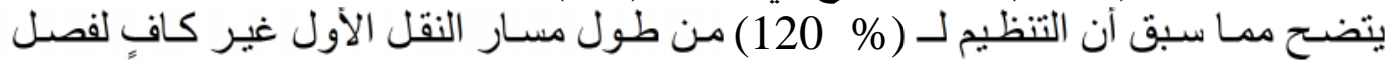
الأعطال التي تظهر ضمن قطاع الحماية الثاني لمرحدّلة قياس المسافة

6.6.2.2.تأثير مصدر القدرة البعيد عن مرحّلة المسافة:

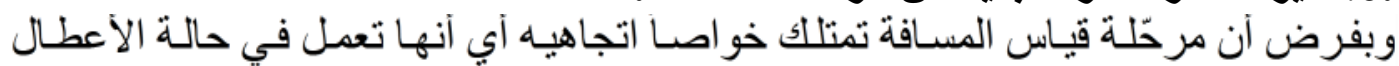

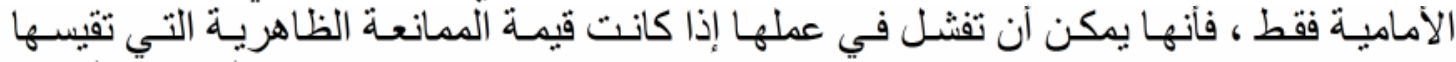

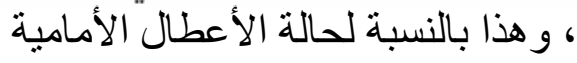
يمكن أن لا تعمل في حالة حدوث عطل في لإل الإني

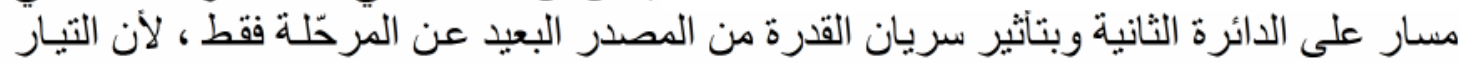

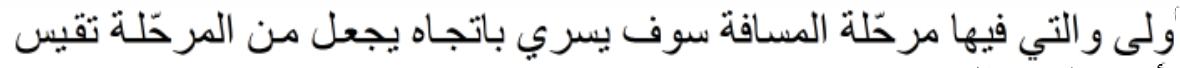

$$
\text { (أي كأنه حالة عطل عكسي) [4]. }
$$

إن أتثير مصدر ي القدرة عند نهايتي خط النقل على مرحدّلة المسافة:

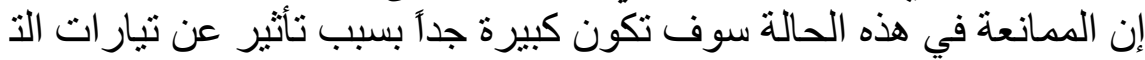

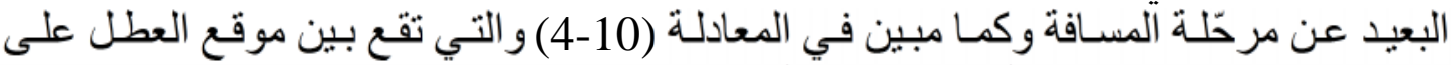

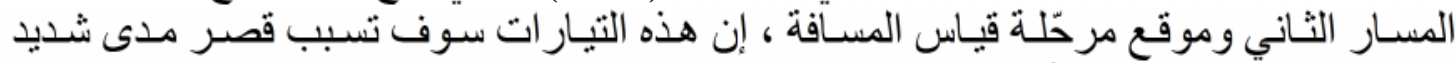

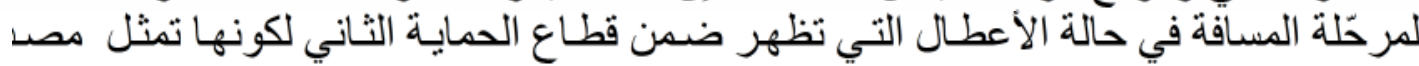
تغذية وسطي ( Intermediate In-Feed Source) وكما يتضح في الثنكلين (3-6) (4-6).

7. تأثير تعويض الحث التبادلى لنظام التعاقب الصفري فى خطوط النقل المزدوجة:

في حالـة وجود موقع العطل وموقع المرحّلـة في المســار نفسـهـ وكمـا في الفقرة (4.1)

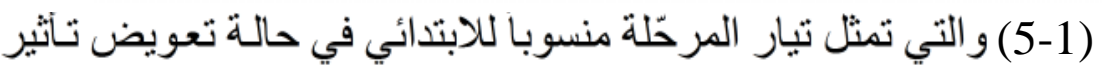
ممانعة الدث التبادلي ، نلاحظ تأثير تعويض الحث التبادلي لنظام التعاقب الصفري فلئ على منطقة 
الحماية ولحالات مستوى القصر سريان القرة المذكورة آنفا ، وكمـا مبين في الأشكال (1-7)

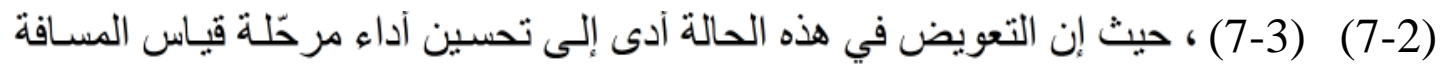
بإلغائه تأثير ممانعة الحث التبادلي لنظام التعاقب الصفري ، وبذلك تصبح الممانعة الظاهرية التي تر اها المرحدلة

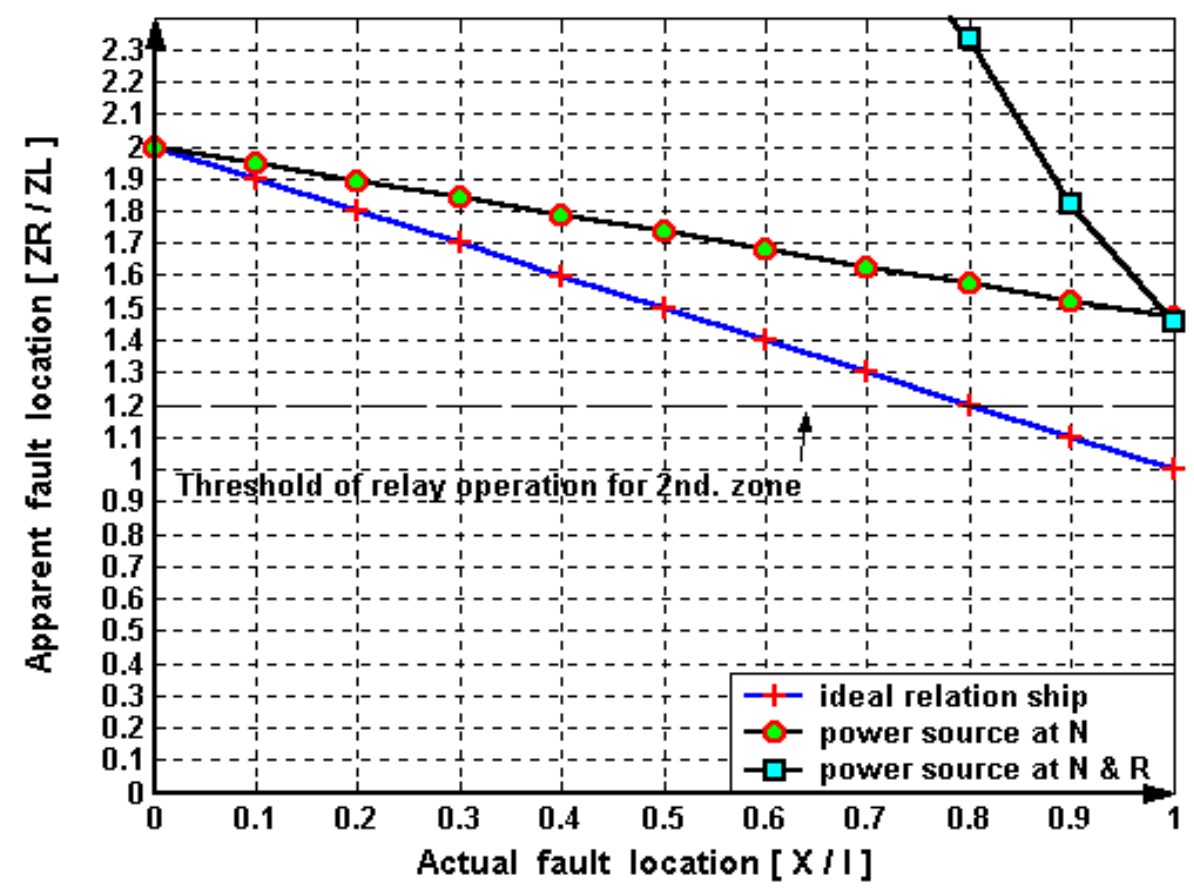

الثكل (3-6) : تأثير الحث التبادلي لنظام التعاقب الصفري على طول منطقة الحماية

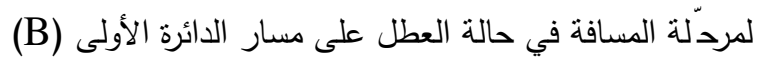




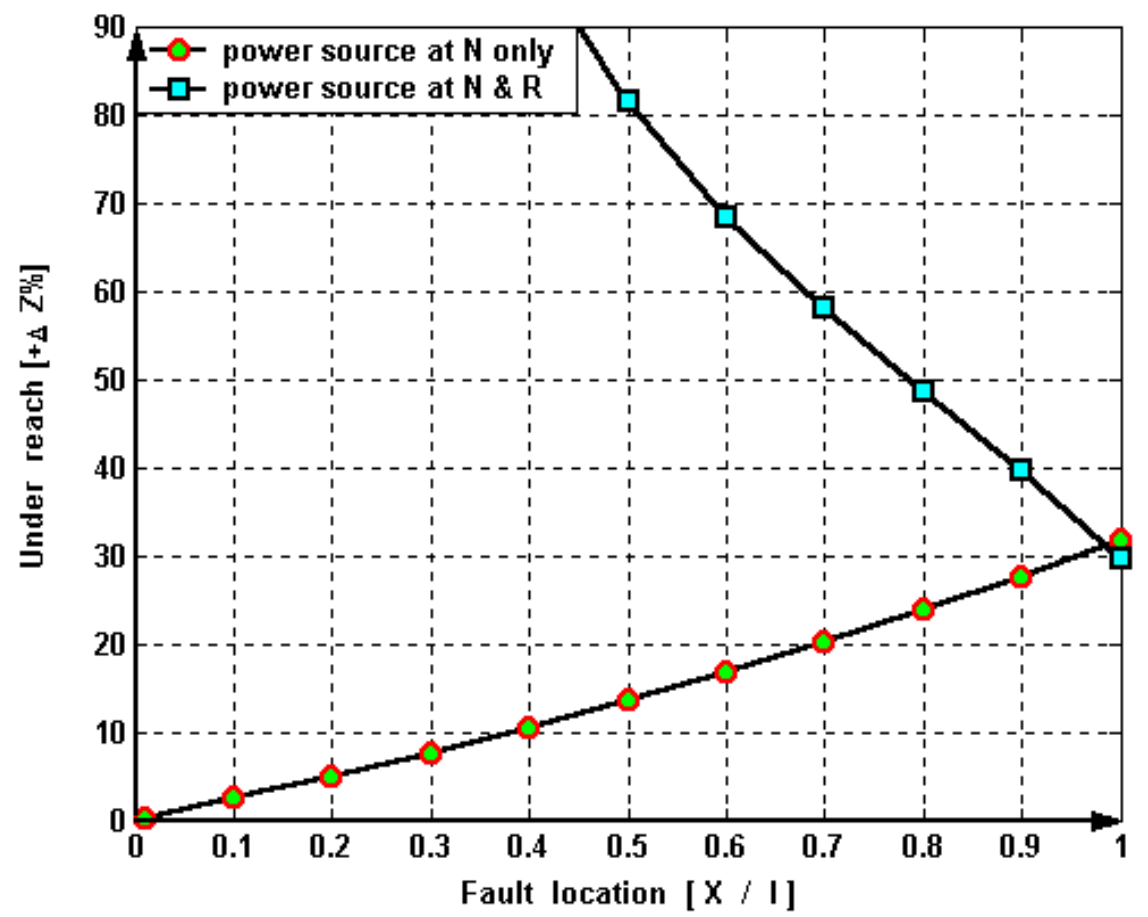

الثكل (4-6) : قيم المدى الحمائي لمرحلة المسافة في حالة العطل على مسار الدائرة (B) 
مساوية للممانعة الفعلية للخط في حالة عطل طور مـع الأرض وكذللك بالنسبة بين موقع العطل الظاهري وموقع العطل الفعلي.

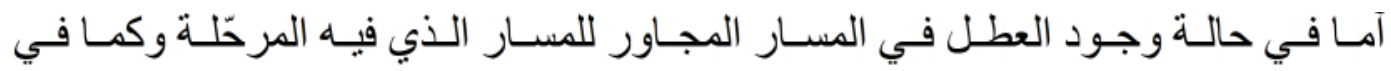

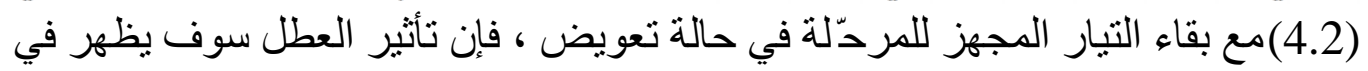

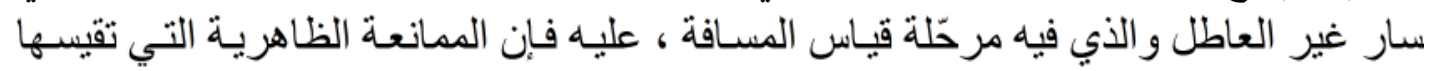

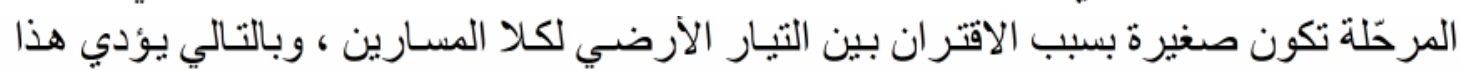

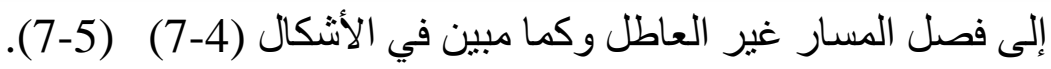

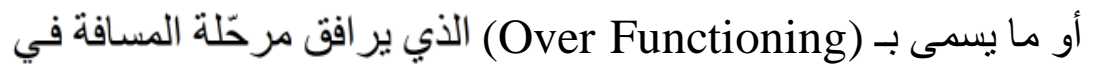

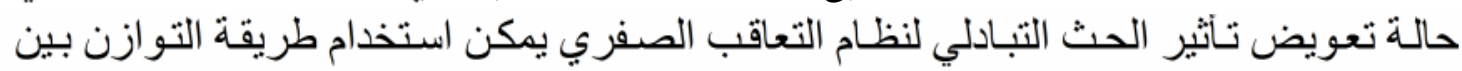

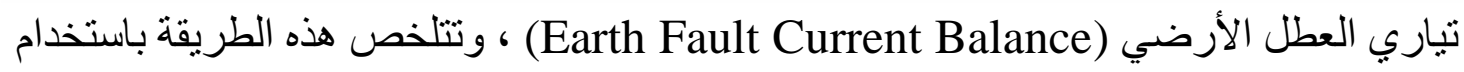

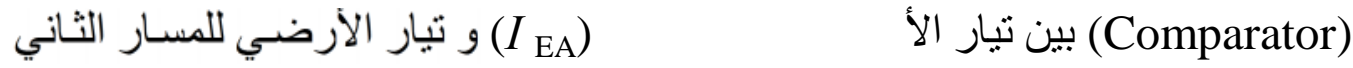

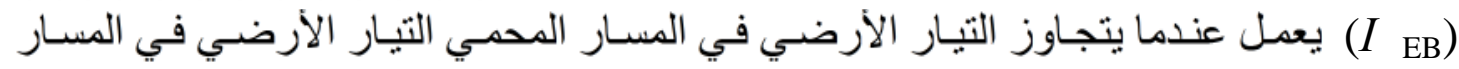

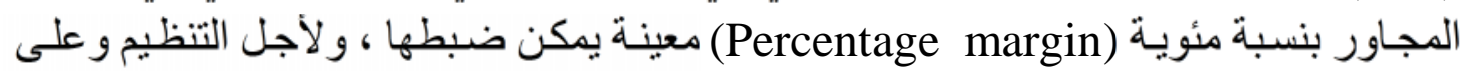

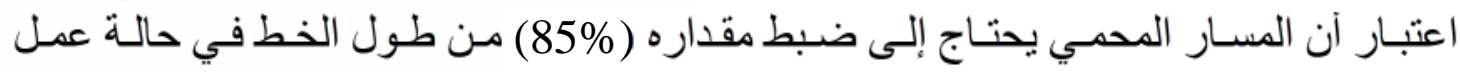

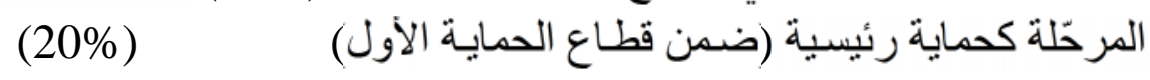

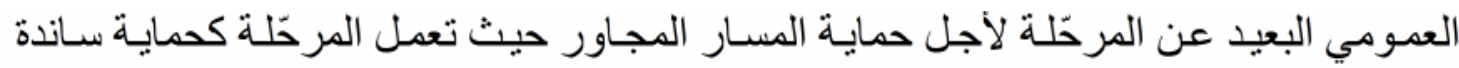

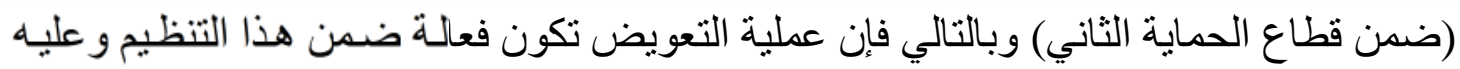

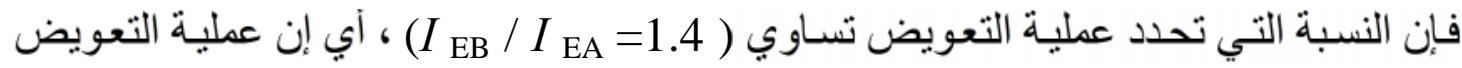

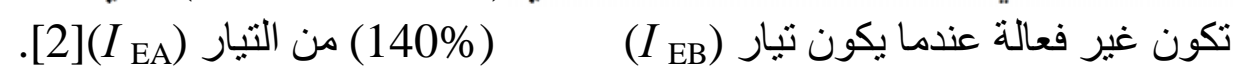

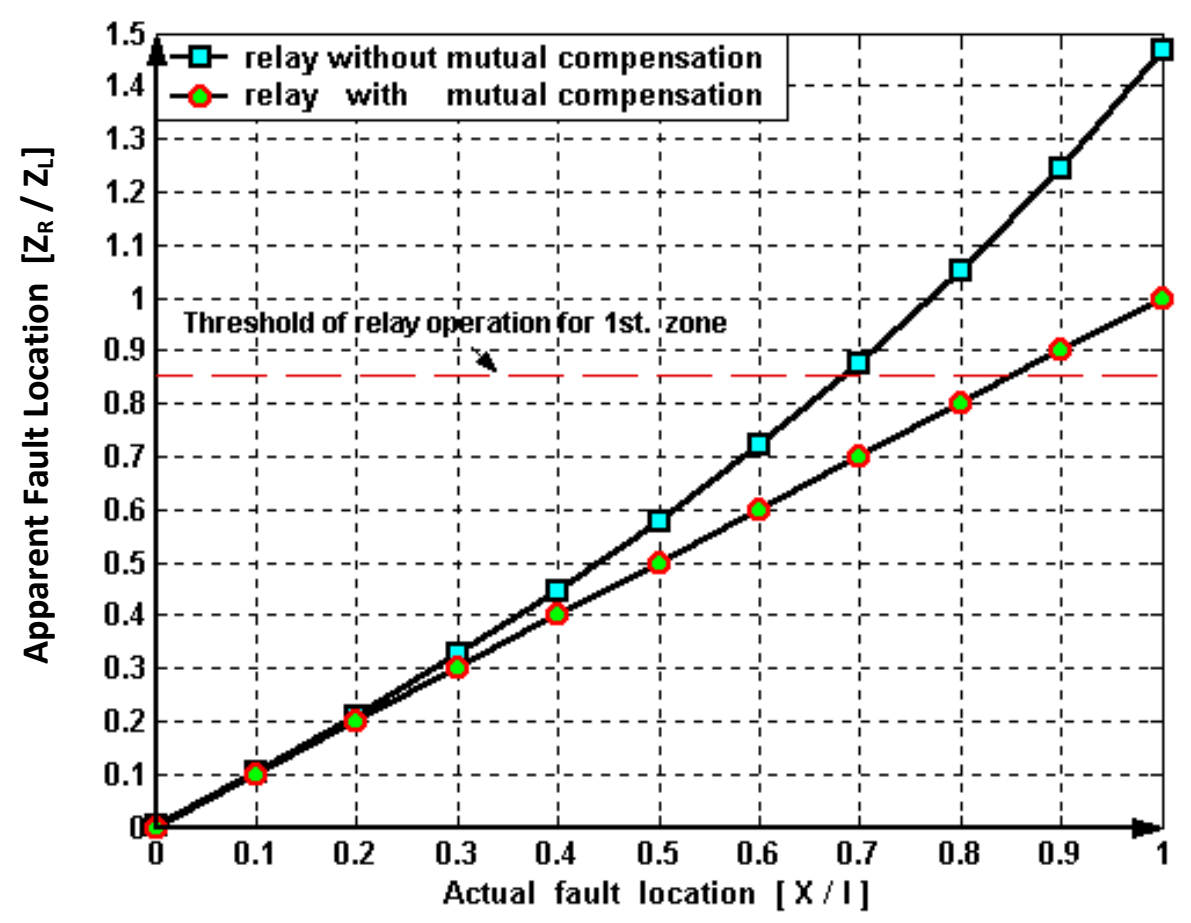


الثكل (1-7): تأثثر تعويض الحث التبادلي على طول منطقة الحماية مع نأثثر المصدر القريب

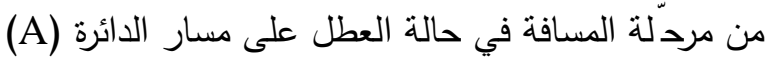

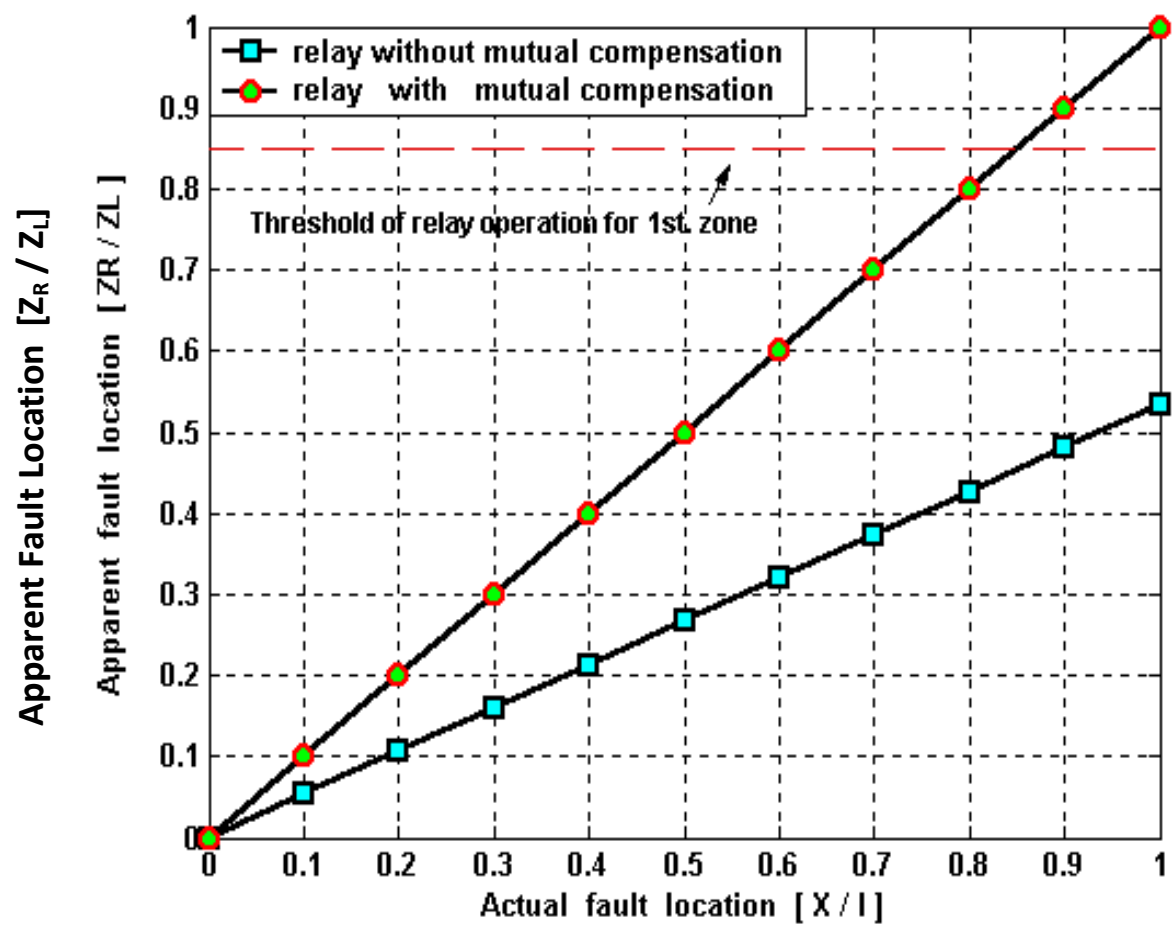

الثكل (2-7): تأثير تعويض الحث التبادلي على طول منطقة الحماية مع تأثثر المصدر البعيد

عن الحماية لمرحلة المسافة في حالة العطل على مسار الائرة (A)

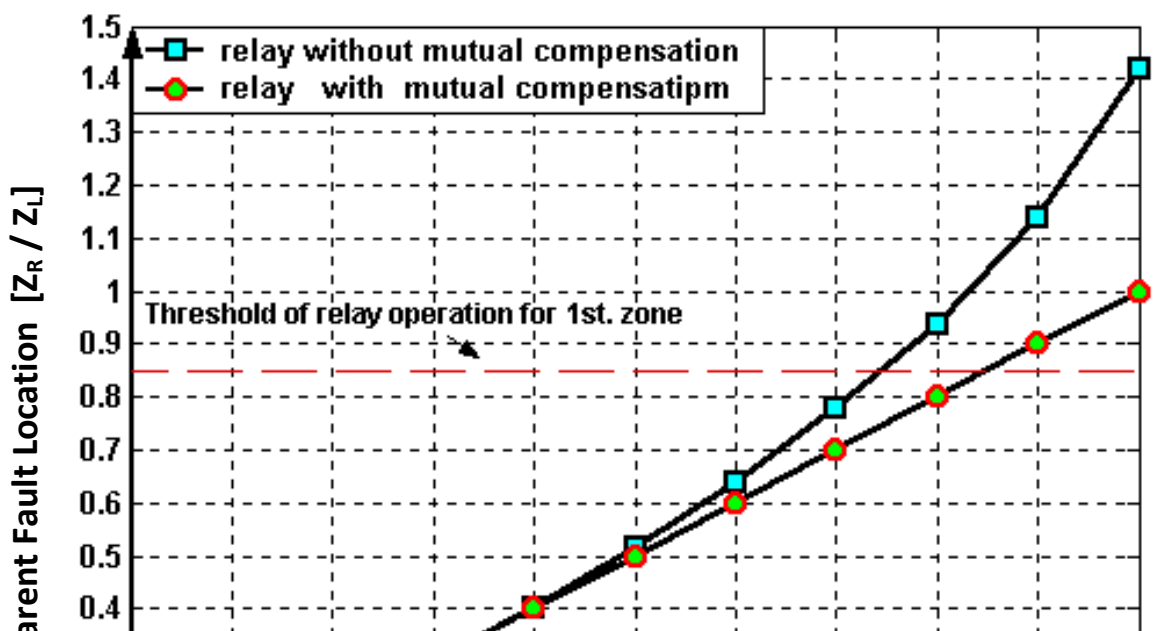




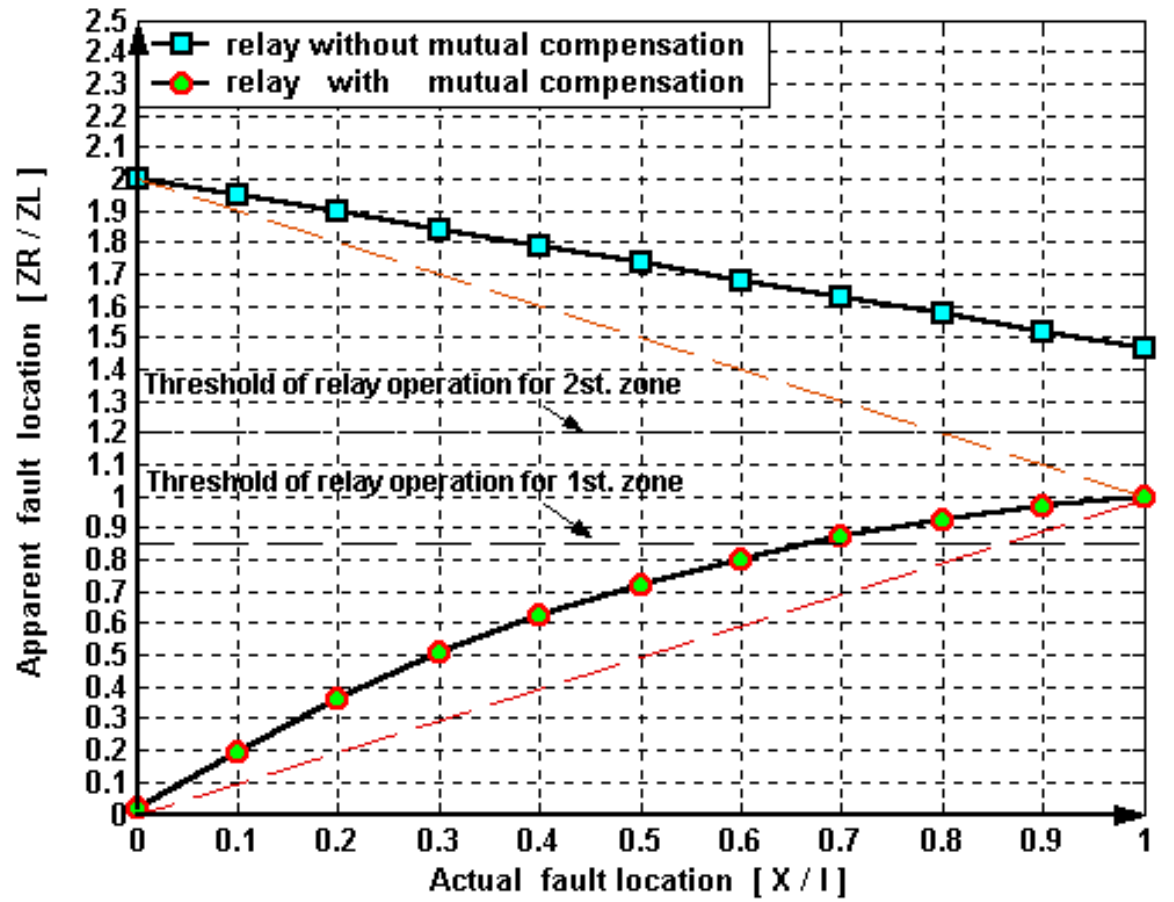

الثكل (4-7): تأثثر تعويض الحث التبادلي على طول منطقة الحماية مع نأثير المصدر القريب

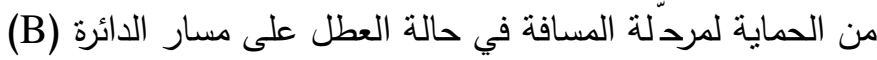

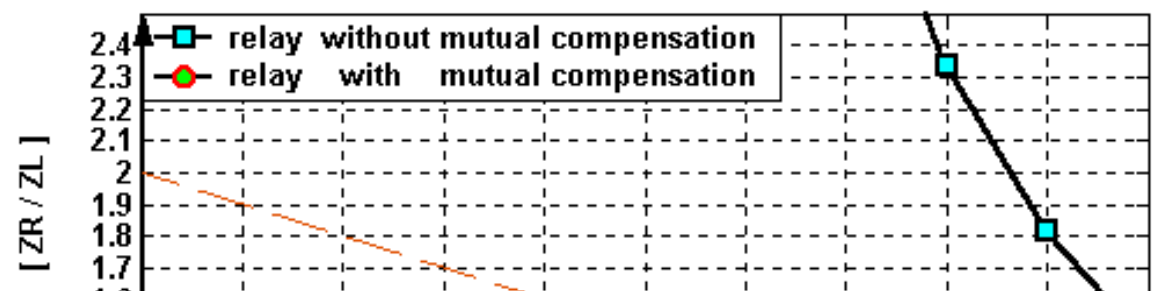




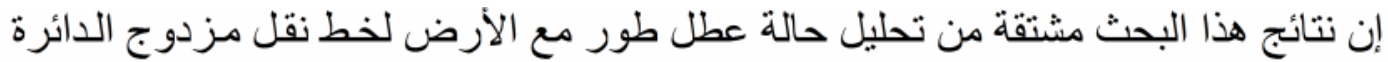

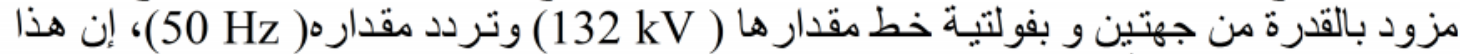

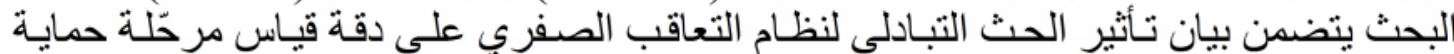

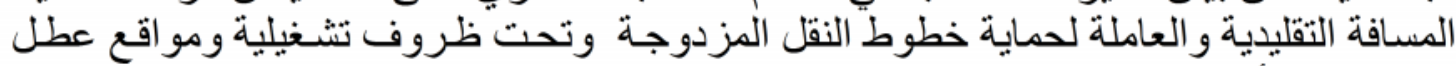
وقد أظهرت النتائج التي تم الحصول عليها من تحليل دائرة العطل ما بلي:

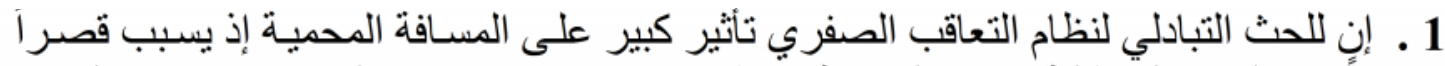

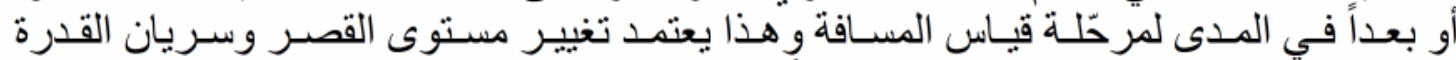
لمصدري آلتغذية عند نهايتي خط النقل فضلا عن موقع العطل.

2 ـ تأثثر اتجاه تياري التعاقب الصفري للمسـارين المتوازيين على مقدار ممانعة الخطاً الناتجـة

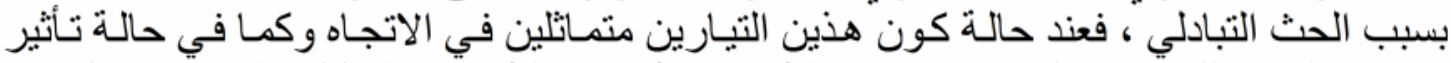

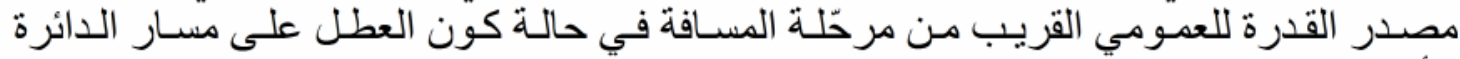

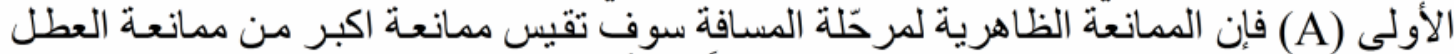

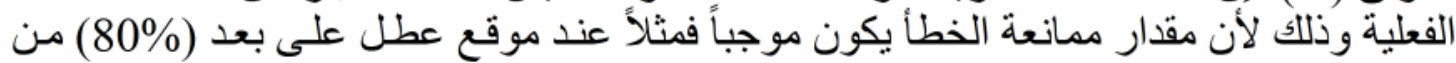

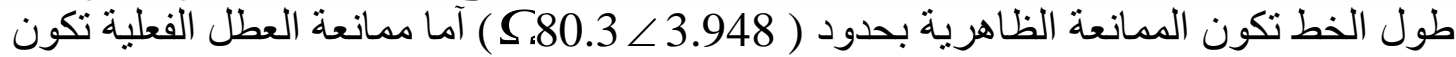

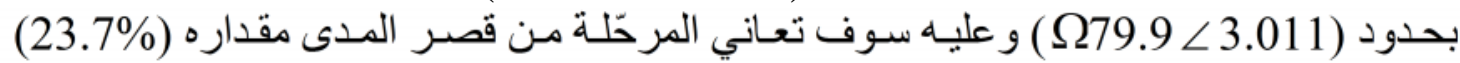

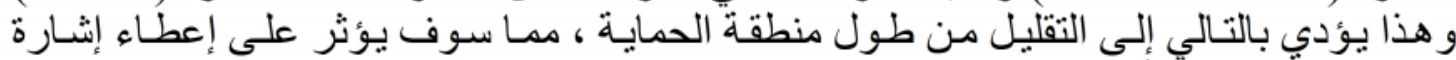

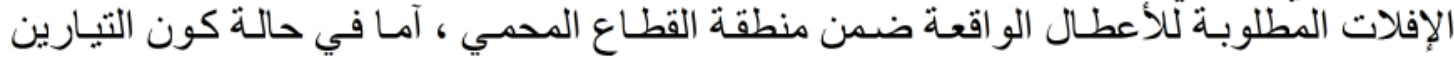




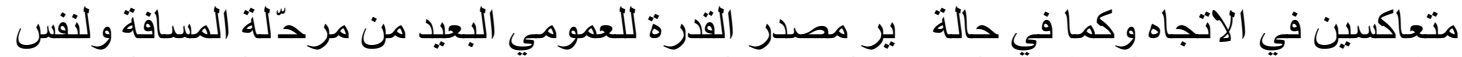

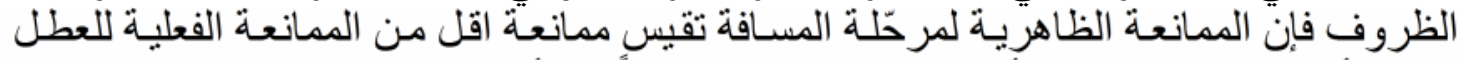

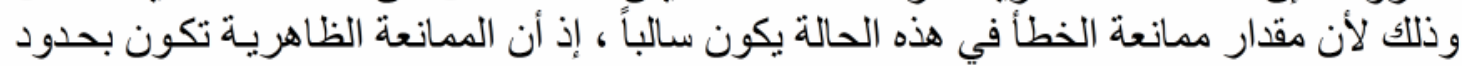

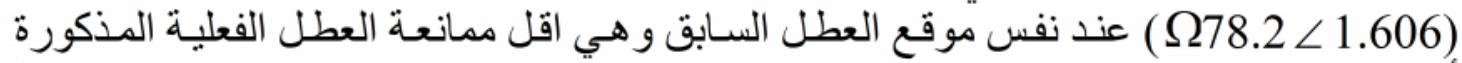



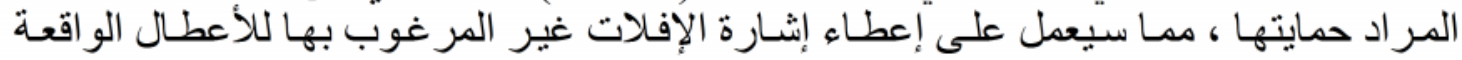
Inter ) منطقة الحماية. وفي كلا الحالتين فإن هذا سوف يؤثر على إثشارة الإفلات البينية البينية

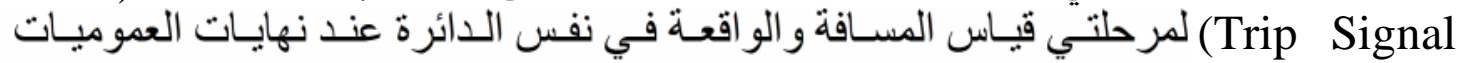

ז. إن استخدام عملية تعويض الحث التبادلي لنظام التعاقب الصفري عن طريق حقن المرحّلة

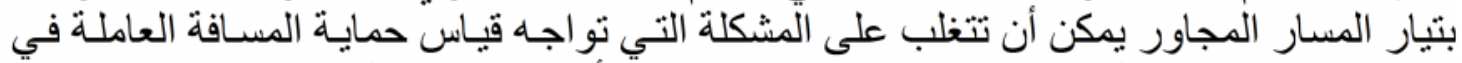

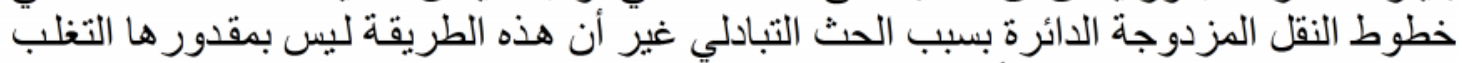

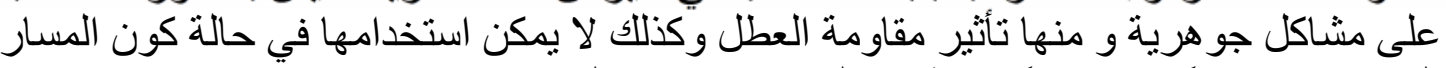

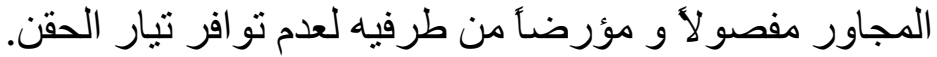

[1] ALSTOM, "Protection and Automation Net Work", Guide, Alstom T\&D Energy Automation and Information, Peter Rush, Levauios - Perret France, 2002.

[2] Gerhard Ziegler, "Numerical Distance Protection, Principles and Application “, $\quad$ Siemens, Erlangen, Germany Publics -MCD-Verl. 1999.

[3] G. E. Alexander and J. G. Andrichak "Application of Phase and Ground Distance Relay to Three terminal Lines", GE [4] J. Mooney and P.E. protection \&control, Malven, PA, 1994 Jackie Peer, "Application Guidelines for Ground Fault Protection”, Schweitzer Engineering Laboratories, Inc. 1997.

[5] M. Sanaye and H. Seyedi, "Simulation, Analysis and Setting of Distance Relays on Double Circuit Transmission Lines", Electrical and computer Engineering Department, Faculty of Engineering, University of Tehran, 2001.

[6] M. M. Saha, D. Novosel, Y. Hu and V. Leitloff, "An Adaptive Scheme for parallel line distance protection", IEEE Trans. on Power Delivery, Vol. 17, No. 1, pp. 105-11, January 2002. 
[7] Matlab Function Reference, "The Language of Technical Computing",

“MATLAB User Guide Version 6.5”, 20 